\title{
Seasonal differences in the subjective assessment of outdoor thermal conditions and the impact of analysis techniques on the obtained results
}

\author{
Noémi Kántor ${ }^{1}$ • Attila Kovács ${ }^{1}$ - Ágnes Takács ${ }^{1}$
}

Received: 6 January 2016 / Revised: 28 February 2016 / Accepted: 29 February 2016

(C) ISB 2016

\begin{abstract}
Wide research attention has been paid in the last two decades to the thermal comfort conditions of different outdoor and semi-outdoor urban spaces. Field studies were conducted in a wide range of geographical regions in order to investigate the relationship between the thermal sensation of people and thermal comfort indices. Researchers found that the original threshold values of these indices did not describe precisely the actual thermal sensation patterns of subjects, and they reported neutral temperatures that vary among nations and with time of the year. For that reason, thresholds of some objective indices were rescaled and new thermal comfort categories were defined. This research investigates the outdoor thermal perception patterns of Hungarians regarding the Physiologically Equivalent Temperature (PET) index, based on more than 5800 questionnaires. The surveys were conducted in the city of Szeged on 78 days in spring, summer, and autumn. Various, frequently applied analysis approaches (simple descriptive technique, regression analysis, and probit models) were adopted to reveal seasonal differences in the thermal assessment of people. Thermal sensitivity and neutral temperatures were found to be significantly different, especially between summer and the two transient seasons. Challenges of international comparison are also emphasized, since the results prove that neutral temperatures obtained through different analysis techniques may be considerably different. The outcomes of this study underline the importance of the development of standard measurement and analysis
\end{abstract}

Noémi Kántor

sztyepp@gmail.com

1 University of Szeged, 2 Egyetem Str., 6722 Szeged, Hungary methodologies in order to make future studies comprehensible, hereby facilitating the broadening of the common scientific knowledge about outdoor thermal comfort.

Keywords Thermal sensation - Neutral temperature · Physiologically equivalent temperature $\cdot$ Regression analysis . Probit model

\section{Introduction}

Hastened by the problems arising with urbanization (UNFPA 2011) and exacerbated with climate change (IPCC 2014), more and more studies deal with outdoor thermal comfort issues in cities with wide variety of background climates all around the world (Chen and Ng 2012; Rupp et al. 2015). Numerous researches evaluated the thermal conditions of different urban structures using one of the several wellestablished thermal comfort indices, for example Physiologically Equivalent Temperature-PET (Höppe 1999). A great part of these studies conducted on-site micrometeorological measurements (e.g., Streiling and Matzarakis 2003; Gulyás et al. 2006; Ali-Toudert and Mayer 2007a; Mayer et al. 2008; Lin et al. 2010; Deb and Ramachandraiah 2011; Holst and Mayer 2011; Hwang et al. 2011; Shashua-Bar et al. 2011; Charalampopoulos et al. 2013; Gómez et al. 2013), while others applied numerical simulations in order to model the thermal comfort or stress conditions that may occur as a consequence of different landscape design strategies even under different future climate scenarios (e.g., Ali-Toudert and Mayer 2006, 2007b; Huttner et al. 2008; Shashua-Bar et al. 2012; Fröhlich and Matzarakis 2013; Müller et al. 2014).

Several analyses were based simply on the standard threshold values of the applied indices. However, adopting the preset threshold values regardless of the geographical location 
raises the question of the result's relevance regarding the thermal perception of local inhabitants. For example, in the case of the aforementioned PET index, the thermal comfort benchmarks are based on the physiological reactions of a Central European man (Matzarakis and Mayer 1996; Matzarakis et al. 1999). For that reason, the original thresholds of PET may overestimate the heat sensitivity of people living in hot arid or even subtropical climates, and underestimate their cold sensitivity. Recognizing this issue, in the last one and a half decade, wide research attention has been paid to the subjective evaluation of thermal comfort conditions in different outdoor and semi-outdoor urban spaces (e.g., Nikolopoulou et al. 2001; Becker et al. 2003; Thorsson et al. 2004; Knez and Thorsson 2006; Lenzholzer 2010; Chen and Ng 2012; Yin et al. 2012; Krüger et al. 2013; Pearlmutter et al. 2014; Tung et al. 2014; Chen et al. 2015).

Numerous studies investigated the relationship between the thermal sensation of local people and various thermal indices in different geographical regions, and found that the original category thresholds of these indices did not describe precisely the actual thermal sensation patterns of subjects. Thus, many studies determined new thermal sensation and comfort thresholds in accordance with the thermal assessment of local people, for example in Taiwan (Lin and Matzarakis 2008), Hungary (Kántor et al. 2012a), Greece (Pantavou et al. 2013), Israel (Cohen et al. 2013; Pearlmutter et al. 2014), and northern China (Lai et al. 2014). Additionally, several papers reported that neutral temperature varies among nations and changes also with the time of the year. Neutral temperature is that temperature at which people feel neither cool nor warm (Fanger 1972). A couple of studies determined neutral temperature simply in terms of air temperature (e.g., Nikolopoulou and Lykoudis 2006; Krüger and Rossi 2011), while others expressed it in terms of more complex thermal indices like Operative Temperature-OT (Spagnolo and de Dear 2003; Yang et al. 2013a), new Standard Effective Temperature-SET* or Outdoor Standard Effective Temperature-OUT_SET* (Nakano and Tanabe 2004; Hwang and Lin 2007; Lin et al. 2011; Xi et al. 2012), PET (Lin 2009; Mahmoud 2011; Cheng et al. 2012; Ng and Cheng 2012; Cohen et al. 2013; Yahia and Johansson 2013; Yang et al. 2013b; Pearlmutter et al. 2014; Chen et al. 2015; Zeng and Dong 2015), Universal Thermal Climate Index-UTCI (Lindner-Cendrowska 2013; Pantavou et al. 2013), or Index of Thermal Stress-ITS (Pearlmutter et al. 2014). These studies demonstrated that people living in different geographical locations with various background climates show different degree of adaptation to the thermal parameters, and do not evaluate them in the same way (e.g., Nikolopoulou and Lykoudis 2006; Kántor et al. 2012b; Yang et al. 2013b). Moreover, even in the case of the same population, seasonal differences were pointed out in neutral temperature and thermal sensitivity (Spagnolo and de Dear 2003; Nakano and Tanabe 2004; Nikolopoulou and Lykoudis 2006; Lin 2009;
Krüger and Rossi 2011; Lin et al. 2011; Mahmoud 2011; Cheng et al. 2012; Ng and Cheng 2012; Cohen et al. 2013; Yahia and Johansson 2013; Chen et al. 2015). Time of the day (Pearlmutter et al. 2014), outdoor or semi-outdoor nature of the physical environment (Hwang and Lin 2007), as well as material and/or function of the outdoor places (Cohen et al. 2013; Saaroni et al. 2015) were also investigated as affecting factors. Appendix Table 10 gives a summary about the studies that assessed the relationship between the thermal environment and its subjective evaluation, and Appendix Fig. 9 shows the geographical location of the cited investigations.

The listed studies were based mostly on transverse questionnaire surveys accompanied with on-site measurement of meteorological variables that affect human thermal comfort. Fitting in this research line, Kántor et al. (2012a) carried out an outdoor thermal comfort survey in Szeged, Hungary, and determined $16.8^{\circ} \mathrm{C}$ as neutral PET (nPET). However, the field measurements covered only two transient seasons: early autumn of 2009 and late spring of 2010. Therefore, the resulted $\mathrm{n} P E T$, as well as the determined Hungarian PET thresholds, have not been considered fully satisfactory to use them for tourism-bioclimatological evaluations. Kovács et al. (2015) utilized a much greater database from the years of 20112012 (including spring, summer, and autumn) in order to point out seasonal differences in the thermal comfort assessment of Hungarians. They reported relatively close autumn and summer $\mathrm{nPET}$ (18.4 and $19.5^{\circ} \mathrm{C}$, respectively) while springtime neutral temperature was identified at lower PET $\left(16.4{ }^{\circ} \mathrm{C}\right)$. The preferred PET (pPET) values occurred at 37.1, 25.1, and $25.7^{\circ} \mathrm{C}$ for spring, summer, and autumn, respectively.

The authors of the present article suspect that this unusual pattern of lower $\mathrm{n} P E T$ and much greater $\mathrm{p} P E T$ in spring may be - at least partly — caused by the uneven distribution of the sample days in the monitored seasons. Namely, springtime data covered the late March-middle May period in both years, and there was a period of 2 to 3 weeks without measurements before the beginning of the summertime campaigns. In contrast, there were no discontinuances between the measurements of summer and autumn, which may explain the much closer $\mathrm{n} P E T$ values and $\mathrm{p} P E T$ values in these seasons. To check this assumption - and in the hope of obtaining more reliable seasonal nPET and $\mathrm{p} P E T$ values - we completed the original 2011-2012 database in 2015 with eight new field surveys conducted in the same period of the day $(10 \mathrm{am}-6 \mathrm{pm})$ in the same city of Szeged according to the same research design. Four of the new measurement days fell in the second half of May, and four of them fell in the middle of June. By this, we covered also the warmest period of spring and incorporated the period of the year with the strongest global radiation occurring in Hungary.

Based on this broadened database with thousands of questionnaires from the transient seasons and summer, this article focuses on the thermal perception patterns of Hungarians. We set the main targets of this paper as follows. 
1. Determining the seasonal differences in the subjective assessment of the thermal conditions

2. Scrutinizing the effect of the frequently applied analysis techniques like probit model and regression analysis on the resulted values of neutral temperature in order to reveal the reliability of international comparison

\section{Methods}

\section{The city of Szeged}

Szeged is located on the Southern Great Plain in the southeast part of Hungary at a latitude of $46^{\circ} 15^{\prime} \mathrm{N}$ and a longitude of $20^{\circ} 09^{\prime} \mathrm{E}$. The city spreads on a flat area at an elevation of about $75 \mathrm{~m}$ above sea level without considerable topographical differences, which enables urban climate results to be generalized (Andrade and Vieira 2007). The region has a warm temperate climate with uniform annual distribution of precipitation. Based on the available climate normal data, the annual amount of precipitation in Szeged is below $500 \mathrm{~mm}$, while the annual sum of sunshine hours reaches almost $2000 \mathrm{~h}$ (Table 1). The 10-m height air velocity $(v)$ values are between 3 and $4 \mathrm{~m} / \mathrm{s}$ throughout the year. The strongest winds occur in March and April. The vapor pressure (VP) peaks in the summer months $(15-16 \mathrm{hPa})$. At the same time, the relative humidity $(R H)$ is around $70 \%$, while it is above $80 \%$ during the winter months. The mean annual air temperature $\left(T_{\mathrm{a}}\right.$-mean $)$ is $10.6{ }^{\circ} \mathrm{C}$; the hottest months are July and August, while January is the coldest time of the year (Table 1). The mean daily maximum temperature $\left(T_{\mathrm{a}}-\mathrm{max}\right)$ is normally above $10{ }^{\circ} \mathrm{C}$ from March to October, therefore this period is more suitable for outdoor activities than the colder months from November to February when the amount of sunshine hours is also lower (lower than $100 \mathrm{~h}$ per month).

Being already one of the warmest cities in Hungary, the urban climate of Szeged is expected to be affected more intensively by the general warming tendencies that have been predicted for the Carpathian Basin, e.g., by Krüzselyi et al. (2011) and Pongrácz et al. (2013). Moreover, Szeged is the third most populated city in the country with more than 160 , 000 residents. All of these features make it very interesting for outdoor thermal comfort investigations. The street network of Szeged forms a circuit-avenue system. There are several landuse types from the densely built-up inner city to the detached housing suburban regions, which allow the development of several local climate zones (Unger et al. 2014).

\section{The complete Hungarian outdoor thermal comfort project}

The Hungarian thermal comfort project consisted of humanbiometeorological measurements and on-site questionnaires conducted with the local people spending their time in different outdoor areas of Szeged. The surveys were carried out in the years 2011, 2012, and 2015. The investigations took place on six recreational areas, including popular urban squares, playgrounds, pedestrian streets, and little parks (Appendices Figs. 10 and 11). Two of the investigated squares received an award of excellence for complete reconstruction from the Hungarian Society for Urban Planning. All survey sites are in the urbanized region of Szeged, therefore large number of visitors may attend on them. The study areas can be characterized with a variety of landscape design solutions, materials, orientations, vegetation cover, etc. For that reason, a wide

Table 1 Climate data in Szeged for the period of 1971-2000 (1961-1990 in the case of VP and RH)

\begin{tabular}{|c|c|c|c|c|c|c|c|c|}
\hline Month & $T_{\mathrm{a}}-\max \left({ }^{\circ} \mathrm{C}\right)$ & $T_{\mathrm{a}}$-mean $\left({ }^{\circ} \mathrm{C}\right)$ & $T_{\mathrm{a}}-\min \left({ }^{\circ} \mathrm{C}\right)$ & Sunshine duration (h) & Precipitation (mm) & $V P(\mathrm{hPa})$ & $R H(\%)$ & $v(\mathrm{~m} / \mathrm{s})$ \\
\hline Jan & 2.8 & -0.8 & -3.8 & 59 & 24 & 5.0 & 86 & 3.5 \\
\hline Feb & 5.7 & 1.2 & -2.6 & 94 & 23 & 5.6 & 83 & 3.9 \\
\hline Mar & 11.6 & 5.9 & 0.5 & 143 & 25 & 6.9 & 74 & 4.1 \\
\hline Apr & 16.9 & 10.8 & 5.2 & 173 & 40 & 8.9 & 69 & 4.0 \\
\hline May & 22.4 & 16.3 & 10.3 & 234 & 51 & 12.3 & 68 & 3.6 \\
\hline Jun & 25.5 & 19.2 & 13.0 & 252 & 68 & 15.1 & 69 & 3.2 \\
\hline Jul & 27.7 & 20.8 & 14.3 & 278 & 53 & 16.0 & 67 & 3.1 \\
\hline Aug & 27.6 & 20.8 & 14.0 & 263 & 56 & 15.8 & 69 & 2.8 \\
\hline Sep & 23.3 & 16.4 & 10.3 & 199 & 37 & 13.2 & 72 & 2.8 \\
\hline Oct & 17.2 & 11.0 & 5.6 & 153 & 35 & 9.8 & 75 & 3.1 \\
\hline Nov & 8.9 & 4.7 & 1.2 & 77 & 38 & 7.6 & 84 & 3.5 \\
\hline Dec & 4.1 & 0.9 & -2.0 & 53 & 39 & 5.8 & 87 & 3.6 \\
\hline Year & 16.1 & 10.6 & 5.5 & 1978 & 489 & 10.2 & 75.3 & 3.4 \\
\hline
\end{tabular}

Source: Hungarian Meteorological Service 
range of small-scale human-biometeorological conditions may be expected on them.

With respect to outdoor activity and human thermal comfort, transient seasons and summer months are of particular importance in Hungary, while the issue of outdoor thermal comfort in winter does not concern a central European city. In view of this, the investigations covered the period from the end of March to the end of October. The data collection lasted from $10 \mathrm{am}$ to $6 \mathrm{pm}$ every day (altogether 78 days) except for the cases when significant precipitation events interrupted the measurements.

\section{Measurements}

Two human-biometeorological stations were used to collect all important atmospheric variables that influence human thermal sensation (Table 2). The stations were placed at two significantly different sites on the same study area, typically in a sunny and shaded (shaded by tree or building) position, or at points with different surface cover (artificial material or grass). Air temperature, relative humidity, and wind speed were measured by two WXT520 Vaisala weather transmitters. Later, we calculated vapor pressure from the measured $R H$ and $T_{\mathrm{a}}$ values. CNR 1 and CNR 4 Kipp and Zonen net radiometers were used to record the short-wave and long-wave radiation flux densities from the environment $\left(K_{\mathrm{i}}\right.$ and $L_{\mathrm{i}}\left(\mathrm{W} / \mathrm{m}^{2}\right)$, i: six directions perpendicular to each other). By means of telescopic tripods, the sensors were placed at a height that is suitable for outdoor thermal comfort investigations: $1.1-1.2 \mathrm{~m}$ above ground level (Mayer 2008; Mayer et al. 2008; Fig. 1). The equipment recorded 1-minute averages of all meteorological variables.

Normally, the arm of the net radiometer faces to south, and in that position the two pyranometers and two pyrgeometers measure $K_{\mathrm{i}}$ and $L_{\mathrm{i}}$ separately from the upper and from the lower hemisphere $\left(K_{\mathrm{u}}, K_{\mathrm{d}}, L_{\mathrm{u}}, L_{\mathrm{d}}\right)$. Both of our tailor-made humanbiometeorological stations are equipped with a rotatable arm that enables the measurement of $K_{\mathrm{i}}$ and $L_{\mathrm{i}}$ also from the four cardinal directions. After 3-min measurement in the normal position, we rotated manually the net radiometers into the second position where it recorded $K_{\mathrm{i}}$ and $L_{\mathrm{i}}$ from east and west $\left(K_{\mathrm{e}}\right.$, $\left.K_{\mathrm{w}}, L_{\mathrm{e}}, L_{\mathrm{w}}\right)$. Again, after 3-min measurement, we turned the arm with $90^{\circ}$ to measure $K_{\mathrm{i}}$ and $L_{\mathrm{i}}$ from south and north $\left(K_{\mathrm{s}}\right.$, $\left.K_{\mathrm{n}}, L_{\mathrm{s}}, L_{\mathrm{n}}\right)$. Considering the 10 am- $6 \mathrm{pm}$ measurement interval, this procedure required 160 rotations per day in the case of each

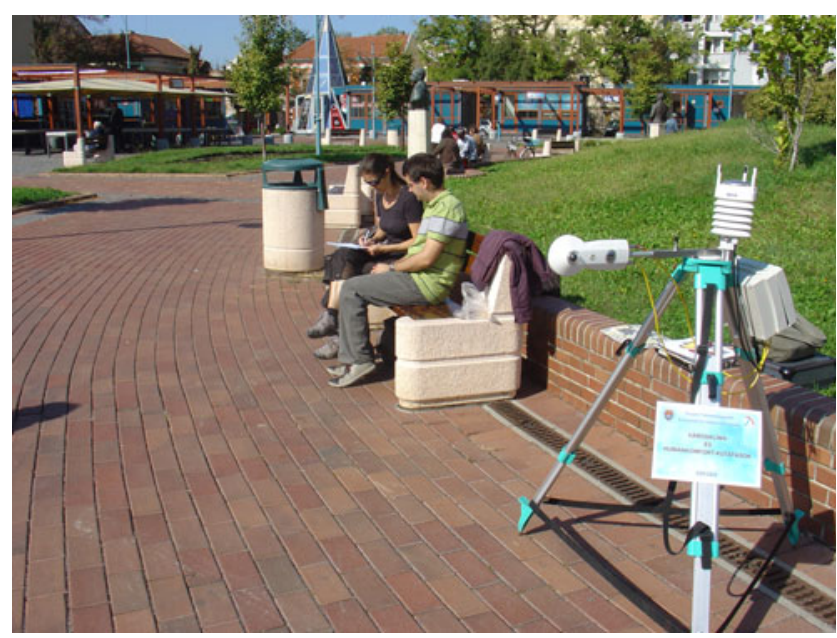

Fig. 1 Outdoor thermal comfort questionnaires supplemented with small-scale human-biometeorological measurements

station. Taking into account the response time of the sensors as well as the time delay due to the manual rotation, we deleted all $K_{\mathrm{i}}$ and $L_{\mathrm{i}}$ that were recorded first time after the rotations.

\section{Index calculation}

Mean radiant temperature $\left(T_{\mathrm{mrt}}\left({ }^{\circ} \mathrm{C}\right)\right)$ is a parameter with primary importance in the field of human-biometeorology. It combines all long-wave and short-wave radiant flux densities into a single value with ${ }^{\circ} \mathrm{C}$-dimension. $T_{\mathrm{mrt}}$ is defined as the uniform temperature of an imaginary black body-radiating surrounding, which causes the same radiant heat exchange for the human body inside this hypothetical environment as the complex 3D-radiant environment in the reality (Fanger 1972; Kántor and Unger 2011). $T_{\mathrm{mrt}}$ is usually calculated for a standardized standing person (Gosling et al. 2014). In the case of this study, $T_{\mathrm{mrt}}$ was determined based on six $K_{\mathrm{i}}$ and six $L_{\mathrm{i}}$ flux densities (Höppe 1992). These were obtained from three consecutive stands of the net radiometer:

$T_{\mathrm{mrt}}=\sqrt[4]{\frac{\sum_{i=1}^{6} W_{i} \times\left(a_{\mathrm{k}} \times K_{i}+a_{1} \times L_{i}\right)}{a_{1} \times \sigma}-273.15}$

In this equation, $a_{\mathrm{k}}$ and $a_{1}$ are absorption coefficients of the clothed human body in the short- and long-wave radiation domain (assumed as 0.7 and 0.97, respectively), $\sigma$ is the Stefan-

Table 2 Instrumentation of the two human-biometeorological stations

\begin{tabular}{lll}
\hline Parameters & Sensors & Accuracy \\
\hline$T_{\mathrm{a}}\left({ }^{\circ} \mathrm{C}\right)$ & Thermocap, WXT520, Vaisala & $\pm 0.3{ }^{\circ} \mathrm{C}$ at $20{ }^{\circ} \mathrm{C}, \pm 0.25{ }^{\circ} \mathrm{C}$ at $0{ }^{\circ} \mathrm{C}$ \\
$R H(\%)$ & Humicap, WXT520, Vaisala & $\pm 3 \%$ at $0-90 \%, \pm 5 \%$ at $90-100 \%$ \\
$v(\mathrm{~m} / \mathrm{s})$ & Ultrasonic anemometer, WXT520, Vaisala & $\pm 3 \%$ or $\pm 0.3 \mathrm{~m} / \mathrm{s}($ the greater) \\
$K_{\mathrm{i}}, L_{\mathrm{i}}\left(\mathrm{W} / \mathrm{m}^{2}\right)$ & Rotatable CNR 1 and CNR 4 net radiometers, Kipp and Zonen & \\
\hline
\end{tabular}


Boltzmann constant $\left(5.67 \cdot \times 10^{-8} \mathrm{~W} / \mathrm{m}^{2} \mathrm{~K}^{4}\right)$, and $W_{i}$ is a direction-dependent weighting factor. Assuming standing reference subject, $W_{i}$ is 0.06 for vertical and 0.22 for horizontal directions (Höppe 1992).

For the purpose of this study, we selected the PET index from the several well-established human-biometeorological indices that can be used to describe the thermal environment, along with the possible thermal perception and degree of physiological stress. This index is regarded as one of the most comprehensive thermal indices for outdoor use to date, and it has been widely used for different outdoor thermal comfort studies under various climatic conditions (Matzarakis et al. 1999; Gulyás et al. 2006; Johansson and Emmanuel 2006; Lin 2009; Matzarakis and Endler 2010; Mahmoud 2011; Cheng et al. 2012; Kántor et al. 2012a, b; Ng and Cheng 2012; Cohen et al. 2013; Yahia and Johansson 2013; Yang et al. 2013b; Pearlmutter et al. 2014; Kovács et al. 2015; Zeng and Dong 2015). PET is derived from the Munich Energy Balance Model for Individuals (MEMI) - a heat balance model of the human body (Mayer and Höppe 1987; Höppe 1999). PET can be defined as the air temperature at which, in a typical indoor setting (without wind and solar radiation), the heat budget of the human body is balanced with the same core and skin temperature as under the complex outdoor conditions to be assessed. The typical indoor thermal environment is described with $v=0.1 \mathrm{~m} / \mathrm{s}, V P=12 \mathrm{hPa}$, and $T_{\mathrm{mrt}}=T_{\mathrm{a}}$. Additionally, the evaluation always refers to a standardized 35-year-old male performing light activity and wearing light business suit (Höppe 1999; Gosling et al. 2014). We performed the PET calculation with the RayMan software (Matzarakis et al. 2007, 2010) by using the measured $T_{\mathrm{a}}, R H, \mathrm{v}$, and the calculated $T_{\mathrm{mrt}}$ values.

\section{Recording the subjective thermal sensation}

The assessment of thermal conditions is highly subjective, meaning that different individuals may evaluate the same thermal environment differently (Mayer 2008). Several field surveys were conducted all around the world in order to reveal these differences between different groups of people, and specify environmental and personal factors that influence the perception of the atmospheric environment (e.g., Nikolopoulou and Steemers 2003; Spagnolo and de Dear 2003; Stathopoulos et al. 2004; Knez and Thorsson 2006, 2008). There are two comprehensive overviews (Chen and Ng 2012; Rupp et al. 2015) of studies focusing on outdoor thermal sensation and perception of thermal comfort, conducted in the last one and a half decade. Most of the investigations were carried out using traverse questionnaire survey technique, when great amount of individuals were interviewed in a variety of environmental conditions (Ng and Cheng 2012).

In the frame of the Hungarian project, we followed the wellestablished international example. Individuals who stayed or walked within a couple of meters to the humanbiometeorological stations were asked to participate in the survey
(Fig. 1). The structured interviews could be completed within $5 \mathrm{~min}$. The questionnaires contained more question blockssometimes complemented with observations by the interviewer-regarding personal factors, area usage, behavioral reactions, evaluation of the area, and subjective assessment of the thermal environment (details were published by Kántor et al. 2012a).

This paper focuses on the interviewees' thermal sensation votes (TSV), which were collected by means of a semantic differential scale with nine main ordered categories ranging from very cold (-4) to very hot (4) and with a central category of neutral (0). Although the generally adopted thermal sensation scales consist of seven categories only, ranging from cold to warm (e.g., Spagnolo and de Dear 2003; Nakano and Tanabe 2004; Hwang and Lin 2007; Lin 2009; Krüger and Rossi 2011; Lin et al. 2011; Mahmoud 2011; Cheng et al. 2012; Xi et al. 2012; Krüger et al. 2013; Lindner-Cendrowska 2013; Pantavou et al. 2013; Yang et al. 2013a, b; Lai et al. 2014; Zeng and Dong 2015; Appendix Table 10), we decided to add two extreme votes to be in better accordance with the wide range of outdoor thermal conditions. Nine-point scales are also known from the literature (Knez and Thorsson 2006, 2008; Cohen et al. 2013; Yahia and Johansson 2013), and these scales have greater potential to rescale thermal comfort indices like PET according to the thermal sensation patterns of local people (Kántor et al. 2012a; Kovács et al. 2015). Similarly to the cold to warm $T S V$ scale of Xi et al. (2012), our subjects were also allowed to select intermediate options beside the main thermal sensation categories. As far as we know, the Hungarian is the first outdoor thermal comfort project that adopted a TSV scale with nine main categories and with intermediate options as well.

\section{Analysis methods}

For the purpose of comparing the subjective thermal sensation patterns of Hungarians regarding the outdoor thermal environment and calculating their neutral temperatures in the investigated seasons, different analysis techniques were applied. The adopted techniques include simple descriptive analysis, ANOVA (one way analysis of variance supplemented with post hoc tests) or its more robust counterpart (Welch test), as well as linear and nonlinear regression analysis, and probit model. The statistical analyses were performed with the PASW Statistics software.

\section{Results}

\section{Interviewees and human-biometeorological background}

On the 78 measurement days, 6764 questionnaires were obtained, but for the purpose of this study we selected 5805 subjects only to whom we were able to attach all meteorological data and valid PET index. Table 3 summarizes the main descriptive statistics regarding the human-biometeorological background of the 
Table 3 Microbiometeorological background of the interviews

\begin{tabular}{llllccc}
\hline & $v(\mathrm{~m} / \mathrm{s})$ & $V P(\mathrm{hPa})$ & $R H(\%)$ & $T_{\mathrm{a}}\left({ }^{\circ} \mathrm{C}\right)$ & $T_{\mathrm{mrt}}\left({ }^{\circ} \mathrm{C}\right)$ & $P E T\left({ }^{\circ} \mathrm{C}\right)$ \\
\hline Mean & 1.2 & 10.2 & 39.7 & 21.4 & 33.2 & 23.1 \\
Median & 1.1 & 10.5 & 37.5 & 21.1 & 30.5 & 22.9 \\
Mode & 0.8 & 11.4 & 28.6 & 13.3 & 31.0 & 27.8 \\
Minimum & 0.1 & 2.2 & 14.8 & 6.9 & 2.7 & 3.6 \\
Maximum & 4.2 & 20.6 & 82.1 & 38.0 & 70.9 & 53.9 \\
25 percentile & 0.8 & 7.6 & 30.3 & 16.1 & 23.4 & 17.1 \\
75 percentile & 1.5 & 12.5 & 46.1 & 26.0 & 42.8 & 29.0 \\
Std. deviation & 0.543 & 3.479 & 12.589 & 6.282 & 13.349 & 8.436 \\
Skewness & 0.812 & 0.006 & 0.889 & 0.215 & 0.482 & 0.210 \\
Std. error of skewness & 0.032 & 0.032 & 0.032 & 0.032 & 0.032 & 0.032 \\
Kurtosis & 0.852 & -0.458 & 0.530 & -0.698 & -0.635 & -0.291 \\
Std. error of kurtosis & 0.064 & 0.064 & 0.064 & 0.064 & 0.064 & 0.064 \\
\hline
\end{tabular}

interviews. The investigated spring, summer, and autumn periods covered the $T_{\mathrm{a}}$-range from 7 to $38^{\circ} \mathrm{C}$. Based on PET index, visitors experienced broader spectrum of thermal conditions from 4 to $54{ }^{\circ} \mathrm{C}$. Half of the subjects fall within the 17 to $29{ }^{\circ} \mathrm{C}$ PET interval, and most of the interviews occurred around $28^{\circ} \mathrm{C}$ PET. The distribution of PET is platykurtic (negative Kurtosis), and it is slightly skewed to right (positive skewness near to zero). This is valid also for the distribution of the interviewees' $T_{\mathrm{a}}$ and $T_{\mathrm{mrt}}$ data. From the ${ }^{\circ} \mathrm{C}$-dimensional indices, $T_{\mathrm{mrt}}$ has the greatest, and $T_{\mathrm{a}}$ has the smallest, standard deviation (SD). Regarding $R H$, the covered humidity range is quite broad (15$82 \%$ ); however, half of the subjects experienced almost the same $R H$ conditions between 30 and $46 \%$. We can observe correspondingly wide range of $V P(2.2-20.6 \mathrm{hPa})$ and narrow interquartile range $(7.6-12.5 \mathrm{hPa})$. Focusing on the wind velocity, three fourth of the questionnaires were conducted either in calm or in light air conditions, i.e., below $1.5 \mathrm{~m} / \mathrm{s}$. The distribution of the $v$ data is leptokurtic and strongly skewed to right.

From 5805 subjects, 2792 were interviewed during spring, 1916 in autumn, and 1097 were asked in summer. Sixty-five percent of the questioned individuals were female. Their age varied between 5 and 95 years, and most of them belonged to the young age group (14 to 30 years). They reported about generally good health conditions, and all of them were Hungarian citizens. About $77 \%$ of the interviewees came to the monitored places to relax. This fact was also reflected by the large proportion of sitting subjects (about $70 \%$ ). Most of them arrived intentionally (63\%), and the common reasons given for attending these places were to meet somebody (40\%), to pass time between classes $(23 \%)$, or simply to enjoy the weather (21\%). Eighty-two percent of the subjects stated that they visit the area at least on a weekly basis.

\section{Subjective thermal sensation}

During the whole survey, interviewees reported most frequently about slightly warm (1) thermal sensation, followed by the warm (2), slightly cool (-1), and neutral (0) votes (Table 4). The occurrence of extreme ( -4 or 4$)$ votes was very rare. It is worth mentioning that more than $20 \%$ of the questioned people selected intermediate values between the main votes; this rate was only $10 \%$ in the neutral group, and it reached almost $50 \%$ at the positive extreme of the TSV scale (Table 4). The most frequently picked intermediates were right at half distance between two integer values (e.g., 3.5, 2.5, etc.).
Table 4 Number of different thermal sensation votes, indicating also the relative frequency of integers and intermediate values within each group

\begin{tabular}{lllll}
\hline Thermal sensation & TSV & Number of subjects & Percentage of main votes & Percentage of intermediates \\
\hline Very hot & 4 & 63 & 52 & 48 \\
Hot & 3 & 347 & 51 & 49 \\
Warm & 2 & 1390 & 73 & 27 \\
Slightly warm & 1 & 1708 & 82 & 18 \\
Neutral & 0 & 849 & 90 & 10 \\
Slightly cool & -1 & 942 & 80 & 20 \\
Cool & -2 & 388 & 74 & 26 \\
Cold & -3 & 101 & 76 & 24 \\
Very cold & -4 & 17 & 65 & 35 \\
Total & & 5805 & 78 & 22 \\
\hline
\end{tabular}


Fig. 2 Distributional statistics of $P E T$ for each thermal sensation vote, as well as the $P E T$ box plots indicating also the mean values (red dots) beside the medians
PET $\left[{ }^{\circ} \mathrm{C}\right]$

\begin{tabular}{|c|rcccccc|}
\hline TSV & \multicolumn{1}{|c}{ N } & Median & Mean & \multicolumn{1}{c|}{ SD } & 25 perc. 75 perc. & IQR \\
\hline 4 & 63 & 33.90 & 34.68 & 6.797 & 30.70 & 38.30 & 7.60 \\
3 & 347 & 33.50 & 33.64 & 6.788 & 29.70 & 38.00 & 8.30 \\
2 & 1390 & 28.90 & 28.70 & 6.658 & 24.30 & 32.50 & 8.20 \\
1 & 1708 & 23.50 & 23.84 & 6.163 & 19.90 & 28.10 & 8.20 \\
0 & 849 & 20.80 & 21.05 & 6.338 & 17.00 & 24.70 & 7.70 \\
-1 & 942 & 16.30 & 16.63 & 5.713 & 12.28 & 20.50 & 8.23 \\
-2 & 388 & 12.15 & 12.79 & 4.706 & 10.30 & 14.28 & 3.98 \\
-3 & 101 & 11.00 & 11.34 & 4.369 & 7.75 & 13.25 & 5.50 \\
-4 & 17 & 9.60 & 10.38 & 2.392 & 8.40 & 12.65 & 4.25 \\
\hline
\end{tabular}

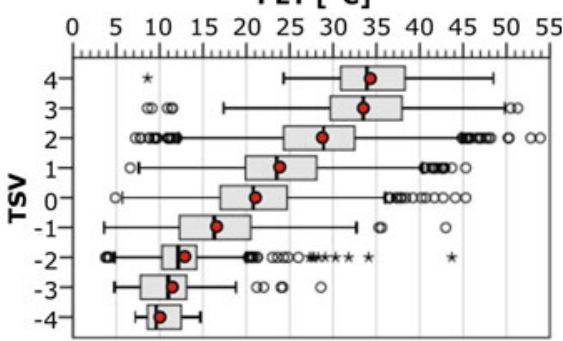

\section{PET distribution at different $T S V$ categories and one option to assess neutral temperature}

For the purpose of the following analyses, the survey data were disaggregated by the rounded values of thermal sensation votes. Figure 2 shows a box plot series of PET by TSV classes and the corresponding descriptive statistics. The central tendency of PET distribution may be expressed either as arithmetic mean or as median. The mean is usually somewhat greater than the median, but they are very close to each other in the case of every group. Although these central values occur at obviously higher PET in the warmer TSV classes, the monotonically increasing trend between them is nonlinear. Additionally, the covered $P E T$ range is very broad in almost every $T S V$ group, except for the extreme votes at the colder end of the $T S V$ scale. The greatest interquartile range (IQR) was observed in the group of subjects who declared they perceived hot (3) and the smallest IQR was found in the cool (-2) category. The overlap between the consecutive boxes (incorporating the middle $50 \%$ of $P E T$, i.e., between the percentiles of 25 and 75) is great, especially between the 3 and 4, as well as the -3 and $-4 T S V$ groups. This can be explained with the small sample in the extreme $(4,-4) T S V$ categories.

The distribution of PET in the $T S V=0$ group has of particular importance in our study because it reveals the thermal conditions at which Hungarians perceived neutral. From the 5805 subjects, 849 reported neutral thermal sensation, i.e., $T S V=0$ (more specifically, $-0.5<T S V<0.5$ ). Figure 2 demonstrates that these people selected neutral TSV despite the wide interval of human-biometeorological conditions. Indeed, PET ranges from 4.9 to $45.3{ }^{\circ} \mathrm{C}$, the percentiles of 25 and 75 indicate quite broad interquartile range (from 17 to $24.7^{\circ} \mathrm{C}, \mathrm{IQR}=7.7{ }^{\circ} \mathrm{C}$ ), and the standard deviation is great $\left(\mathrm{SD}=6.34^{\circ} \mathrm{C}\right)$. The median and mean PET values in the neutral group are 20.8 and $21.05{ }^{\circ} \mathrm{C}$, respectively. It is important to note that $\mathrm{Ng}$ and Cheng (2012) referred the central values (mean PET, median $P E T)$ at $T S V=0$ as neutral temperature.

To reveal seasonal differences, and because of the disharmonious sample sizes (420 neutral votes in spring, 124 in summer, 305 in autumn), it was reasonable to conduct a seasonal analysis too. When we separated the interviewees who had neutral $T S V_{\mathrm{S}}$ according to seasons, we found mean PET at $19.2{ }^{\circ} \mathrm{C}$ for spring, at $26{ }^{\circ} \mathrm{C}$ for summer, and at $21.6{ }^{\circ} \mathrm{C}$ for autumn. The corresponding medians were very close to these values (Fig. 3). We revealed significant (sig. $=0.000$ ) differences between the mean PET values using either one way ANOVA supplemented with any of the post hoc tests or the Welch test (the latter is a robust test of equality of means, which is preferable when the sample sizes and the variances are different in the subgroups). Median test - which assumes nothing about the distribution, making it a good choice as the distribution of PET varies by seasons - was also performed and confirmed that the median values of the three seasons are significantly different (asymp. sig. $=0.000$ ).

In the case of our study, both median and mean values proved to be suitable to explore $\mathrm{n} P E T$ differences among the different seasons. However, regarding the topic of neutral temperature in general, authors recommend the usage of median from the central values of PET distribution at $T S V=0$ instead of arithmetic mean. The arithmetic mean is sensitive to the outliers that may
Fig. 3 Distributional statistics of $P E T$ for the neutral TSV group separated by seasons (mean PET values are also indicated on the box plots as red dots)

\begin{tabular}{|l|r|r|r|}
\hline \multirow{2}{*}{} & \multicolumn{3}{|c|}{ SEASON } \\
\cline { 2 - 4 } & \multicolumn{1}{|c|}{ spring } & summer & autumn \\
\hline Median & 420 & 124 & 305 \\
Mean & $\mathbf{1 8 . 5 5}$ & $\mathbf{2 5 . 8 0}$ & $\mathbf{2 2 . 4 0}$ \\
SD & $\mathbf{1 9 . 2 2}$ & $\mathbf{2 5 . 9 8}$ & $\mathbf{2 1 . 5 5}$ \\
Variance & 5.573 & 5.367 & 6.543 \\
Minimum & 31.059 & 28.810 & 42.813 \\
Maximum & 6.50 & 16.10 & 4.90 \\
Percentile 25 & 36.60 & 45.30 & 44.10 \\
Percentile 75 & 15.80 & 22.40 & 18.20 \\
IQR & 21.60 & 28.98 & 25.10 \\
& 5.80 & 6.58 & 6.90 \\
\hline
\end{tabular}

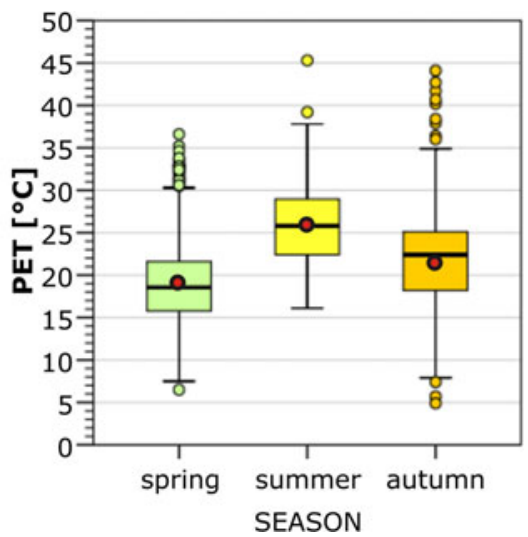


cause problems (may distort the resulted neutral temperatures) in the case of researches with small sample sizes. The median is however a more robust measure that can be used even if the PET distribution has many outlier values.

\section{Regression analysis-another approach to determine neutral temperature}

Neutral temperature has been determined most frequently by analyzing the relationship between the collected subjective thermal sensation votes and the objective measure(s) of thermal environment-PET or other temperature-type indices like $S E T^{*}, O U T \_S E T^{*}$, or UTCI (Appendix Table 10). Considering the whole Hungarian database $(N=5805)$, individual TSV values were plotted against the PET index (Fig. 4a). Linear regression fits the TSV-PET data pairs relatively well, with the following equation:

$$
\mathrm{TSV}=0.1154 \times \mathrm{PET}-2.0596\left(R^{2}=0.463\right)
$$

According to the determination coefficient, $46 \%$ of the variability in Hungarians' subjective thermal sensation can be explained by the PET index with considerable statistical significance $(0.000)$. This is in line with previous estimations reporting that merely $50 \%$ of the variance in the subjective thermal assessments may be explained by physicalphysiological conditions (e.g., Nikolopoulou and Steemers 2003; Lindner-Cendrowska 2013; Pearlmutter et al. 2014).
Fig. 4 Regression analysis between the interviewees' subjective thermal sensation and the PET index using linear and quadratic fits as well. Different sub-cases include $T S V$ vs. PET (a), weighted $M T S V$ vs. PET (b), and $M T S V$ vs. $P E T$ (c)
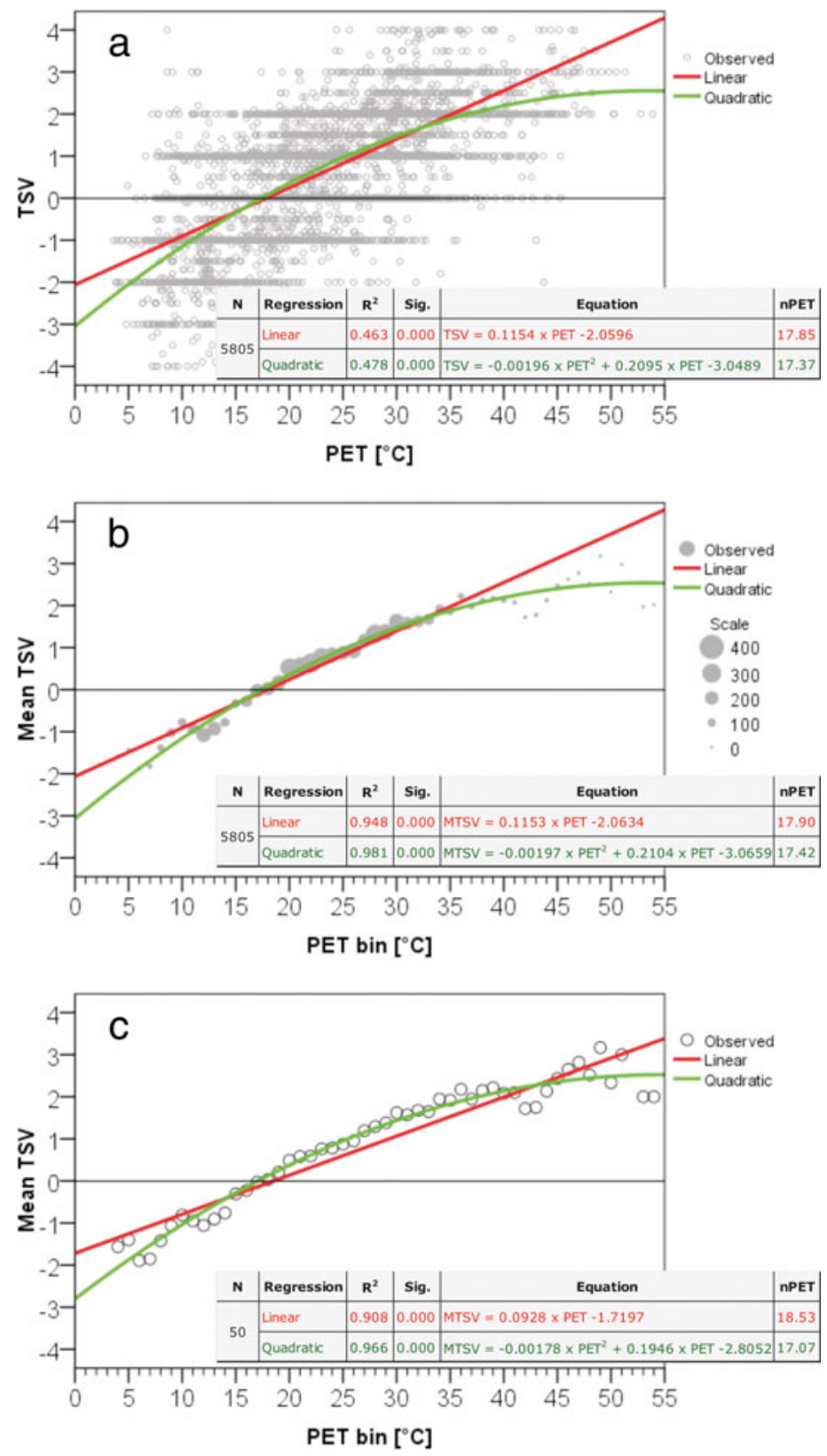
The slope of the regression line represents the sensitivity of Hungarians against the changes of PET, i.e., their thermal sensitivity. The slope value of 0.1154 reveals that about $8.7^{\circ} \mathrm{C}$ increase in PET brings one category increment in Hungarians' TSV. Substituting TSV $=-0.5$ and $T S V=0.5$ values into the linear equation assigns the lower and upper thresholds of the neutral PET category at 13.5 and $22.2{ }^{\circ} \mathrm{C}$, respectively. This neutral zone, which is in accordance with the thermal assessment of Hungarian subjects, occurs at lower PET values than at the generally adopted original PET scale $\left(18-23{ }^{\circ} \mathrm{C}\right)$, which was established for Central European people (Matzarakis and Mayer 1996; Matzarakis et al. 1999). The much wider neutral interval in Hungary demonstrates considerably lower thermal sensitivity, i.e., greater tolerance against the changes of outdoor thermal conditions. This finding is in agreement with the outcomes of many other studies (e.g., Nikolopoulou and Steemers 2003; Thorsson et al. 2004; Nikolopoulou and Lykoudis 2006).

The fitted linear function intersects the neutral $(T S V=0)$ line at around $18^{\circ} \mathrm{C} \mathrm{PET} \mathrm{(Fig.} \mathrm{4a).} \mathrm{Neutral} \mathrm{temperature} \mathrm{can} \mathrm{be}$ exactly determined by solving the regression equation for $T S V=0$; this procedure results in $17.85^{\circ} \mathrm{C}$.

Figure 4a demonstrates clearly that thermal sensation varies greatly among subjects even in the same thermal environment (i.e., at the same PET value). In order to reduce the individual differences, numerous studies adopted the method of using mean thermal sensation votes (MTSV) according to bined temperature values instead of the usage of the actual TSV S. In this study, we adopted $1{ }^{\circ} \mathrm{C}$ wide PET intervals (Fig. 4b, c). There are numerous examples for linear regression using $1{ }^{\circ} \mathrm{C}$ wide temperature bins from different regions ranging from Southeast Asia (e.g., Hwang and Lin 2007; Lin 2009; Lin et al. 2011; Lai et al. 2014; Zeng and Dong 2015) to hot arid and Mediterranean climate regions (Mahmoud 2011; Pantavou et al. 2013). Examples can be found for 0.5 or $1.2{ }^{\circ} \mathrm{C}$ wide bins too (Yang et al. 2013a, 2013b; Krüger et al. 2013). Using MTSV instead of individual TSV implied that the number of data pairs have been reduced from more thousands to the number of the applied temperature bins. Authors of this paper propose the solution of Nakano and Tanabe (2004) and Yang et al. (2013a) who weighted MTSV with the number of cases per temperature bin, thereby they retained the original case number.
Comparing Fig. 4b, c with Fig. 4a, slight differences can be observed between the regression lines as well as between the resulted $\mathrm{n} P E T$ values, which was caused by the slight modification of the adopted regression techniques. The values of determination coefficients increase in a great extent $\left(R^{2}>0.9\right)$ due to the eliminated individual differences. Neutral PET occurred at almost the same value in the case of the weighted MTSV vs. PET linear regression than at the original $T S V$ vs. PET technique, but in the third instance - using $M T S V$ values without weighting them with the case numbers per $P E T$ interval — we found a bit higher nPET.

In order to examine the effect of different regression functions on the resulted nPET, Fig. 4 shows second-degree polynomial (quadratic) regressions as well, beside the liner functions. This comparison was inspired by a couple of researchers who applied quadratic regression beside (or instead of) the linear fit (e.g., Kántor et al. 2012a, 2012b, LindnerCendrowska 2013; Kovács et al. 2015).

Figure 4 demonstrates that quadratic regression improved slightly the strength of the relationship (increased $R^{2}$ values) in every sub-case, and resulted in a change of $n P E T$ values as well. We can observe the greatest differences in the case of the third sub-set, i.e., $M T S V$ vs. $P E T$, without weighting: linear $\mathrm{n} P E T$ is $18.53{ }^{\circ} \mathrm{C}$, while quadratic $\mathrm{n} P E T$ is $17.07{ }^{\circ} \mathrm{C}$. More important differences are caused regarding the assessed thermal sensitivity of people. Based on the new equations, Hungarians reacted more sensitively to the increments in PET in the cooler parts of the temperature-scale, while their responses varied modestly in the warmer domain, revealing an enhanced heat tolerance.

For seasonal comparison, we applied only the regression sub-technique of weighted MTSV vs. PET (Table 5). Quadratic regression can be characterized with slightly better $R^{2}$ values in all investigated cases. This function resulted in almost the same nPET in spring and autumn, and clearly higher summer value. On the contrary, using linear regression, the obtained $\mathrm{n} P E T$ in spring and autumn became slightly different, and summer $\mathrm{n} P E T$ became lower than those in the transient seasons. It is worth noting that this value falls very near to the lower end of the covered PET range in summer (Table 5). Neutral PET values derived from quadratic equations correspond better to the seasonal trends one may expect in Hungary.

Table 5 Seasonal regression functions between $P E T$ and weighted $M T S V$, and the resulted neutral temperatures $\left({ }^{\circ} \mathrm{C}\right)($ sig. $=0.000$ in all cases)

\begin{tabular}{|c|c|c|c|c|c|c|c|c|}
\hline \multirow[t]{2}{*}{ Season } & \multirow[t]{2}{*}{ Number } & \multirow[t]{2}{*}{ PET range } & \multicolumn{3}{|l|}{ Linear regression } & \multicolumn{3}{|l|}{ Quadratic regression } \\
\hline & & & Equation & $R^{2}$ & $\mathrm{n} P E T$ & Equation & $R^{2}$ & $\mathrm{n} P E T$ \\
\hline Spring & 2792 & $4-47$ & $\mathrm{MTSV}=0.1158 \mathrm{PET}-2.0446$ & 0.92 & 17.7 & MTSV $=-0.00267 \mathrm{PET}^{2}+0.2386 \mathrm{PET}-3.3109$ & 0.96 & 17.2 \\
\hline Summer & 1097 & $16-54$ & $\mathrm{MTSV}=0.1080 \mathrm{PET}-1.7713$ & 0.84 & 16.4 & MTSV $=-0.00387 \mathrm{PET}^{2}+0.3522 \mathrm{PET}-5.4443$ & 0.94 & 19.7 \\
\hline Autumn & 1916 & $4-48$ & $\mathrm{MTSV}=0.1124 \mathrm{PET}-2.0833$ & 0.91 & 18.5 & MTSV $=-0.00232 \mathrm{PET}^{2}+0.2150 \mathrm{PET}-3.0452$ & 0.96 & 17.4 \\
\hline
\end{tabular}




\section{Probit model- the third approach to obtain neutral temperature}

Another popular way of determining neutral temperature applies probit model. Probit analysis is generally used to investigate many kinds of dichotomous (binary) response experiments in a variety of fields ranging from toxicology to ecology. In the field of thermal comfort, Ballantyne et al. (1977) suggested applying probit analysis to identify preferred temperature (actually, according to the recent nomenclature, they determined neutral temperatures).

Since dichotomous response variables may have two possible outcomes only (e.g., 1-0, yes-no), we divided our database according to a carefully selected $T S V$ criterion. A set of binary response variables could be created based on the interviewees' thermal sensation, for example, recoding thermal sensation votes into $T S V<0$ and $T S V \geq 0$ categories. $T S V \leq 0$ and $T S V>0$ was another useful option regarding the aimed neutral temperature. The outcome of our binomial response variables (i.e., the occurrence of certain TSV groups) was influenced by PET, as regressor variable, according to a sigmoid function (Fig. 5). The yellow transition curve on Fig. 5a describes the probability of people changing their thermal sensation from cooler than neutral $(T S V<0)$ to neutral or warmer $(T S V>=0)$, thus entering the neutrality zone, and the red transition curve describes the probability of people altering their thermal sensation from neutral or cooler $(T S V<=0)$ to warmer than neutral $(T S V>0)$, thus exiting the neutrality zone. With the increment of $P E T$, the probability of warmer vote-options increased, while the probability of cooler vote-options decreased (Fig. 5).

Reviewing the literature of outdoor thermal comfort studies, one may find more options to designate neutral temperature by utilizing the sigmoid curves of the probit model (Appendix Table 10). Figure 5 gives a set of graphical illustrations that help in elucidating the basic idea of the different approaches. We applied these techniques on the whole Hungarian database in order to reveal whether they result in the same neutral temperature. $1^{\circ} \mathrm{C}$ wide PET intervals were utilized in every case.

a) Based on the transition curves $T S V \geq 0$ and $T S V>0$, Nikolopoulou and Lykoudis (2006) determined neutrality zones and neutral temperatures for seven European cities. First, they obtained those temperatures at which $50 \%$ of the interviewees would be on the verge of changing their $T S V$ to the next higher value (indicated by smaller dashed arrows on Fig. 5a). Then they identified the center value of the neutrality zone as neutral temperature (greater solid arrow on Fig. 5a). This method resulted in $17.6^{\circ} \mathrm{C}$ for the Hungarians. The same results would be obtained by using the $T S V<0$ and the $T S V \leq 0$ transition curves, however, only for the $50 \%$ probability level. Similarly, the $T S V<0-T S V>0$ or the $T S V \leq 0-T S V \geq 0$ curve pairs would result in the same neutrality zones and the same neutral temperatures. Note that any other level of probability would result in different outcomes.

b) Many researchers from East Asia adopted probit model in another way to derive preferred temperatures, e.g., in Taiwan (Hwang and Lin 2007; Lin 2009; Lin et al. 2011), and in Singapore and Changsha, China (Yang et al. 2013a, b). Although they utilized thermal preference votes (TPV) above zero and below zero to obtain preferred temperatures, we can easily convert the train of their thought into TSV and neutral temperature. According to this approach, the
Fig. 5 Probit model subtechniques aiming to ascertain neutral temperature from the probability curves of certain TSV groups in the function of $P E T$
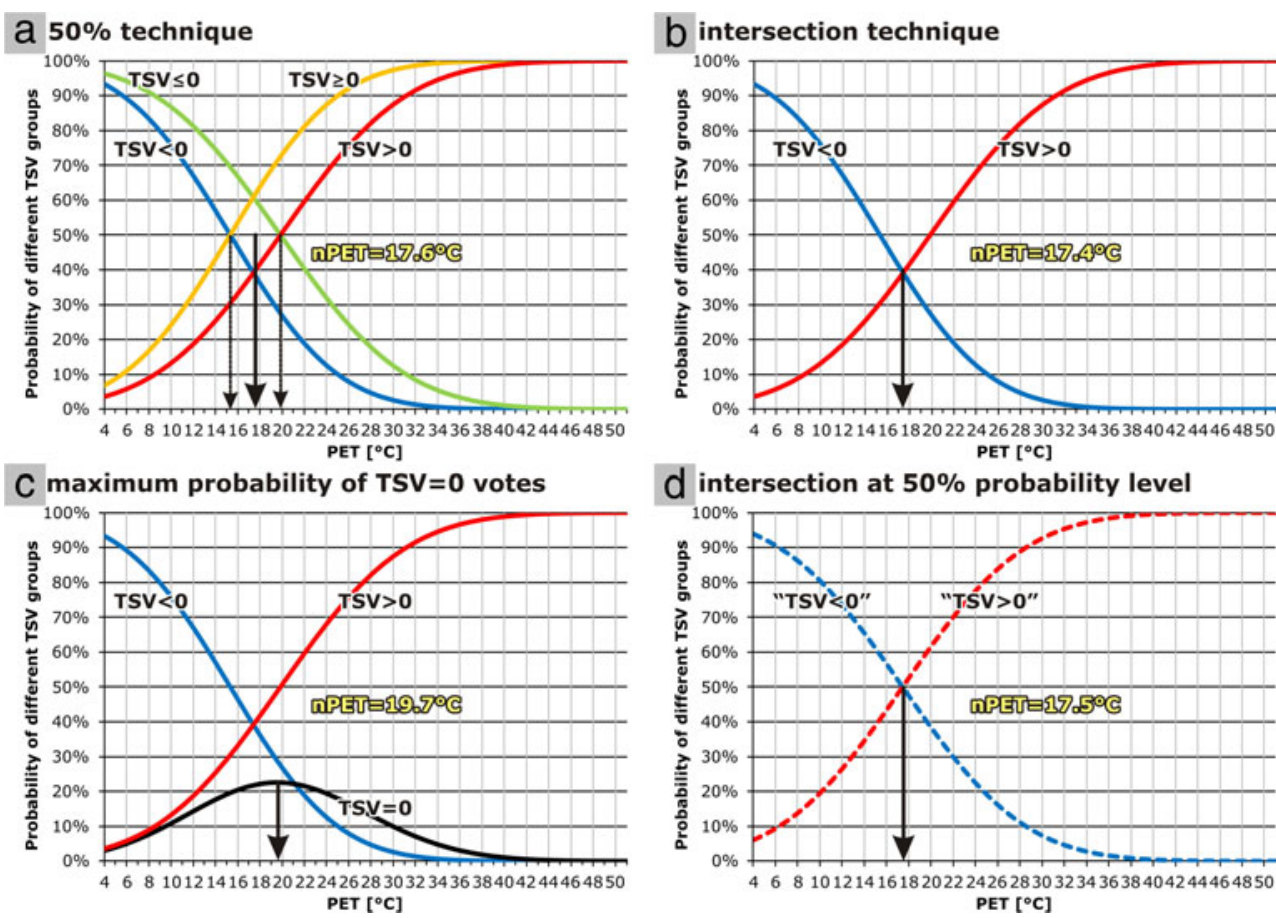
intersection of transition curves $T S V<0$ (cooler than neutral) and $T S V>0$ (warmer than neutral) would be assumed to indicate neutral temperature (Fig. 5b). For Hungary, the intersection occurs at $17.4{ }^{\circ} \mathrm{C} P E T$. Note that the corresponding probability level is below $40 \%$.

c) Although the formerly presented probit sub-techniques resulted in very similar $\mathrm{n} P E T$ values in the case of Hungary, and the ideas behind them broadened considerably the scientific knowledge in the field, authors of the present article suggest another approach. Note that the $T S V<0$ and $T S V>0$ curves intersect each other always below the $50 \%$ level of probability, and considering a vertical axis, the two transition curves are usually not symmetrical to each other. That is, the rate of decline in the probability of $T S V<0$ votes does not equal generally to the rate of incline in the probability of $T S V>0$ votes. Therefore, the intersection point indicates merely the PET value at which the probability of these two vote groups equals, which does not necessarily coincide with the maximum probability of neutral thermal sensation $(T S V=0)$. Thus, it seems reasonable to depict the probability of $T S V=0$ votes (calculated by substituting the probabilities of $T S V<0$ and $T S V>0$ from $100 \%$ ) against the PET index and determine the PET where this curve reaches its maximum. (The original idea is based on the work of Kántor et al. 2014.) The suggested new approach resulted in obviously different $\mathrm{n} P E T$ in Hungary, $19.7^{\circ} \mathrm{C}$ (Fig. 5c).

d) There is one more probit sub-technique in the field of outdoor thermal comfort literature applied by Spagnolo and de Dear (2003; Sydney, Australia) and later by Yahia and Johansson (2013; Damascus, Syria). They converted $T S V=0$ votes randomly and equally into $T S V<0$ and $T S V>0$ groups. As a result, these two groups became complementary, i.e., the sum of their probability in every temperature bin became $100 \%$. This means that the transition curves intersect each other exactly at $50 \%$ level of probability (Fig. 5d). Based on the Hungarian data, this approach indicated $\mathrm{n} P E T$ at $17.5^{\circ} \mathrm{C}$.

The goodness of fit of the probit models to the observed frequencies of the corresponding $T S V$ groups was evaluated according to the nonparametric chi-square $\left(\chi^{2}\right)$ test. Chi-square test is utilized for measuring the goodness of fit, typically between the observed data and expected distribution (Gosling et al. 2014). The probit models fitted very well in the case of both $T S V<0$ and $T S V>0$ groups. (For $T S V<0: \chi^{2}=1015.740, \mathrm{df}=48$, sig. $=0.000$, and for $T S V>0: \chi^{2}=194.53, \mathrm{df}=48$, sig. $=0.000$ ). The resulted $\mathrm{n} P E T$ values were very close to each other based on the sub-techniques $a(50 \%), b$ (intersection) and $d$ (intersection at $50 \%$ ). Nevertheless, approach $c$ has a great advantage that it works with the probability level of neutral votes directly. Besides, in the case of considerably different course of probability lines (like in the case of the mentioned earlier studies), one may suspect that techniques $a$ and $b$ would not result in the same neutral temperatures.

Table 6 summarizes the seasonal $\mathrm{n} P E T$ values based on the probit sub-techniques $a, b$, and $c$. The original approaches, $a$ and $b$, led to very similar $\mathrm{n} P E T$ values with the same seasonal order: spring has the lowest $\mathrm{n} P E T$, followed by autumn and summer. Probit sub-technique $c$ resulted in quite different values: these occurred at higher PET, and the order between them was different. However, we should point out that the fit of the $T S V<0$ model was very poor in summer ( $\operatorname{sig}=0.998)$; therefore, any of the presented summertime $\mathrm{n} P E T$ values must be treated with caution.

\section{Ascertainment of local thermal sensation zones}

Some of the above-presented regression and probit techniques can be utilized also for ascertaining new PET category boundaries in accordance with the subjective thermal perception of local subjects. The regression technique allows determining new PET benchmarks by substituting $-3.5,-2.5,-1.5,-0.5$, etc. $T S V$ values into the obtained linear or quadratic equations (Fig. 6a, b). The linear fit led to $8.7^{\circ} \mathrm{C}$ wide thermal sensation zones (TS-zones). The quadratic regression, which expressed more closely the thermal sensitivity of Hungarians, resulted in narrower TS-zones at lower PET values and broader TS-zones in the warmer regions of the scale. This indicates that local population has greater cold sensitivity and lower heat sensitivity, i.e., Hungarians tolerate better the warmer environmental conditions from early spring to late autumn. The two regression types led to different TS-categories on the investigated PET domain. Linear fit allowed us to define the lower PET threshold of slightly cool $(-1)$ and the higher threshold of hot $(+3)$ categories, while quadratic regression allowed us to designate the lower PET boundary of cool $(-2)$ and the higher boundary of warm (+2) class (Fig. 6a, b).

In the case of the probit-based approaches, a set of binary response variables were created based on $T S V$, adopting the ideas
Table 6 Goodness of fit of the seasonal probit models in the two $T S V$ groups, as well as the resulted neutral temperatures $\left({ }^{\circ} \mathrm{C}\right)$ according to sub-techniques $a$ (50\%), $b$ (intersection), and $c$ $(\max$ of $T S V=0)$

\begin{tabular}{|c|c|c|c|c|c|c|c|c|}
\hline \multirow[t]{2}{*}{ Season } & \multirow[t]{2}{*}{$\mathrm{N}$ of PET bins } & \multicolumn{2}{|c|}{ Model TSV $<0$} & \multicolumn{2}{|c|}{ Model TSV > 0} & \multicolumn{3}{|c|}{$\mathrm{n} P E T$ by technique } \\
\hline & & $\chi^{2}$ & Sig. & $\chi^{2}$ & Sig. & $\mathrm{a}$ & $\mathrm{b}$ & $\mathrm{c}$ \\
\hline Spring & 43 & 138.671 & 0.000 & 64.685 & 0.011 & 17.3 & 17.2 & 18.4 \\
\hline Summer & 38 & 16.119 & 0.998 & 62.656 & 0.004 & 19.1 & 19.0 & 19.8 \\
\hline Autumn & 45 & 1901.928 & 0.000 & 196.208 & 0.000 & 18.0 & 17.7 & 20.8 \\
\hline
\end{tabular}


Fig. 6 Designation of local thermal sensation zones of PET index based on different approaches: linear regression (a), quadratic regression (b), cumulative probability of TSV categories (c), and individual probability of certain TSV categories (d)
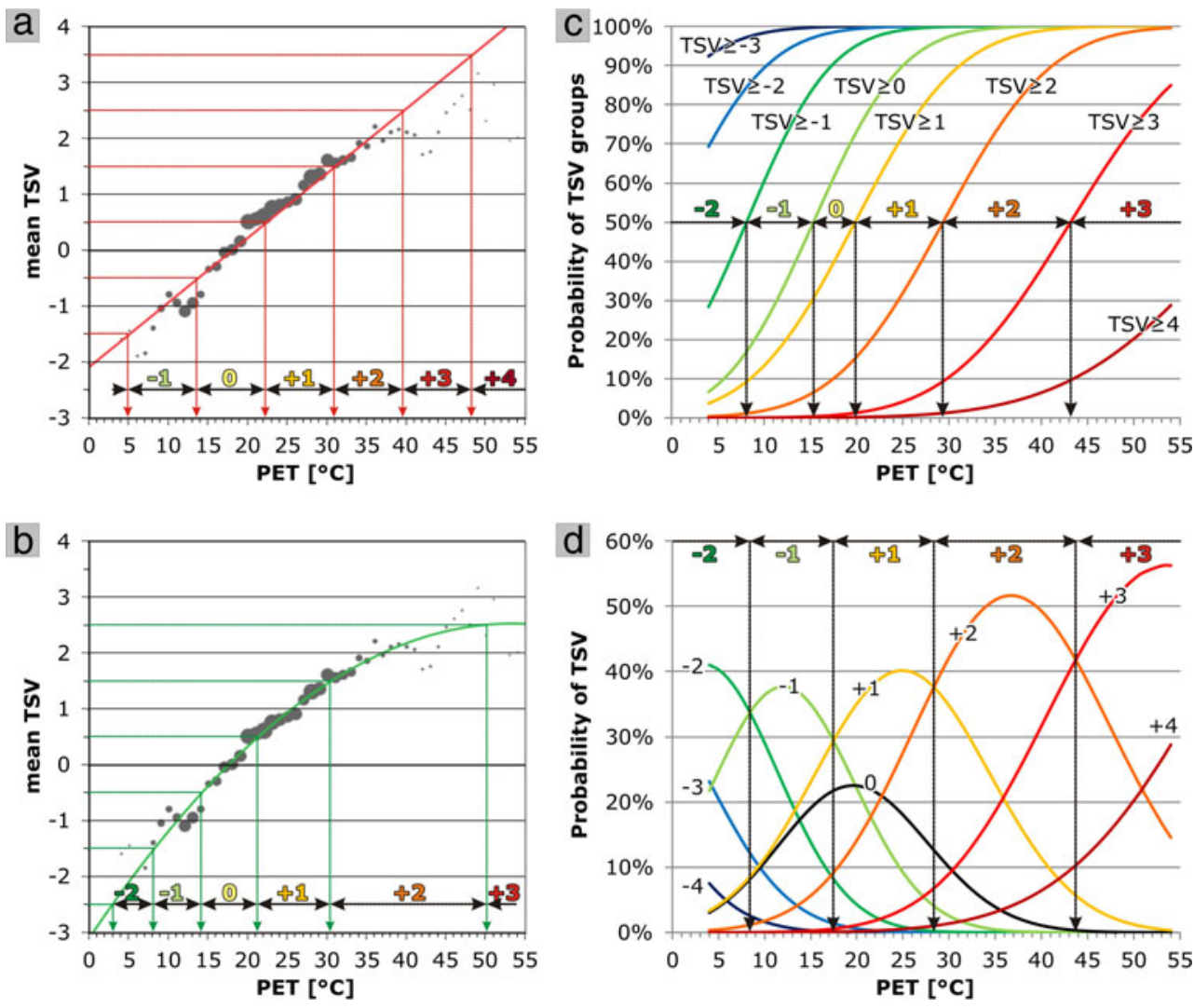

of Ballantyne et al. (1977) and Nikolopoulou and Lykoudis (2006). The transition curves on Fig. 6c describe the probability of people changing their thermal sensation votes from a cooler category to an adjacent warmer category. Using the $50 \%$ probability level, we were able to allocate the boundary temperatures (PET) of TS-zones from slightly cool $(-1)$ to warm $(+2)$. This approach, similarly as quadratic regression, resulted in different width of TS-zones. However, while Fig. $6 \mathrm{~b}$ revealed monotonically increasing interval width, in the case of Fig. 6c, the narrowest TS-zone belongs to the neutral category.

Using the probit model technique, we calculated the individual probability values for each TSV category by subtracting the greater than equal-type cumulative probability values from the prior values: $\mathrm{P}[T S V=n]=\mathrm{P}[T S V \geq n]-\mathrm{P}[T S V \geq n+1]$ (Fig. 6d). As a result, we obtained similar chart-type like Pearlmutter et al. (2014) based on ordinal logistic regression, but the cited authors did not determine TS-categories based on their probability chart. There is however an option to ascertain TS-zones through identifying the intersections of adjacent probability lines. In the case of the Hungarian data, cool $(-2)$ category prevails below $8.5^{\circ} \mathrm{C}$, and slightly cool $(-1)$ takes the leading role between 8.5 and $17.5^{\circ} \mathrm{C}$. However, along the entire length of the PET scale, the probability of neutral votes ( 0$)$ was always lower than the probability of slightly warm votes $(+1)$; thus, it did not allow us to define neutral TS-zone in terms of PET. It seems that in every case the greatest portion of people perceived either cooler or warmer than neutral. Slightly warm $(+1)$ TS-zone was set between 17.5 and $28.5^{\circ} \mathrm{C}$, then warm category $(+2)$ prevailed until $44{ }^{\circ} \mathrm{C}$ when hot $(+3)$ votes took the leading role (Fig. $\left.6 \mathrm{~d}\right)$. It is worth mentioning that except for the missing neutral zone, the last technique resulted in very similar TS-zones than the other probit-based sub-technique (Fig. 6c, d).

Figure 7 offers a graphical overview on the seasonal TSzones obtained via the abovementioned PET-rescaling techniques. Quadratic regression and the transition curve (cumulative probability) method resulted in the most similar results among the four techniques, although the neutral zone became obviously narrower in the case of the transition curve method. Adopting the approach based on the intersection of the individual probability lines, we were not able to define the borders of neutral zone in any seasons.

\section{Discussion}

\section{Comparison of the resulted $\mathrm{n} P E T$ values}

Table 7 compares the overall and seasonal nPET values calculated for Hungary based on the main analysis approaches and adopting different sub-techniques. Members of the first approach (PET distribution's central value at the TSV $=0$ group) led to the highest neutral temperatures. Besides, these values differ mostly from the others in the table. Within this technique, the median and mean PET deviates mostly in autumn. 


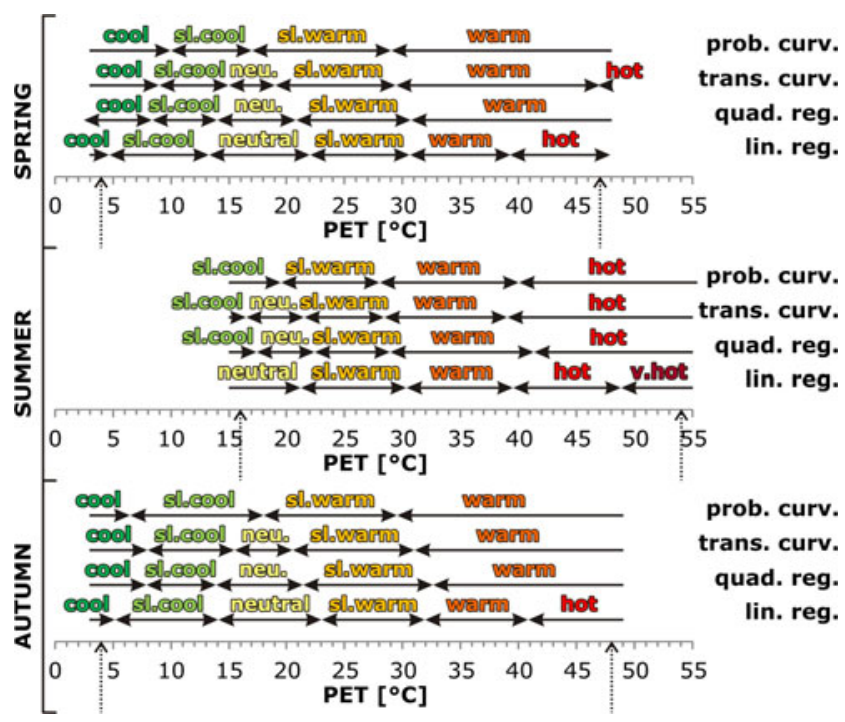

Fig. 7 Seasonal thermal sensation zones based on different analysis approaches (dashed arrows indicate the lowest and highest PET values obtained in the investigated seasons)

Canvassing the second approach, the regression subtechniques, "TSV vs. PET" as well as "weighted MTSV vs. $P E T$ " equations resulted in almost the same $\mathrm{n} P E T$ values. However, the "MTSV vs. PET" regressions, which have been applied most frequently in the outdoor thermal comfort literature (Appendix Table 10), led to somewhat different results, and this applies for linear and quadratic regressions as well (Table 7). Clear seasonal tendencies were obtained through quadratic functions which are in agreement with the seasonal expectations: spring and autumn values are close to each other, and the summertime $\mathrm{n} P E T$ is obviously higher. The $\mathrm{n} P E T$ values derived from linear regressions deviate greatly from the abovementioned "expected" seasonal order; we can observe the lowest values in this group in summer (Table 7).

When applying probit model, the first two sub-techniques (half distance between the transition curves at $50 \%$ probability level, and intersection of the transition curves) resulted in very similar $\mathrm{n} P E T$ values to those obtained from the quadratic regressions "TSV vs. PET" and "weighted MTSV vs. PET." Additionally, the seasonal order of these results is in agreement with the expected trends.

Although the seasonal order meets our expectations in the cases of the median and mean techniques too, they resulted in considerably higher $\mathrm{n} P E T$ values compared to the other techniques. This is especially true for summer (Table 7). In the case of the newly introduced probit sub-technique (maximal probability of $T S V=0$ votes), the seasonal $\mathrm{nPET}$ values ascend in the order of spring, summer, and autumn. The most surprising seasonal order (summer, spring, and autumn) was obtained through linear regression.

We can observe the greatest scatter among the different $\mathrm{n} P E T$ techniques in summer (Table 7). This may be explained as follows:

- The sample size was considerably lower in this season, which is the consequence of the lack in human resources because of the summertime vacation.

- Most of the thermal sensation votes fell in the warmer end of the $T S V$ scale in summer. Indeed, while the portion of positive votes were $53 \%$ in autumn and $58 \%$ in spring, the relative frequency of $T S V>0$ votes in summer exceeded $80 \%$. The small amount of neutral and cooler votes lowered the credibility of designation of $\mathrm{n} P E T$.

\section{Comparison with earlier studies}

It is very likely that the abovementioned distributing factors might cause difficulties during other studies in the cases of small sample size in any of the investigated seasons, or if TSV votes cumulate far away from 0 due to the seasonal thermal conditions. It is worth mentioning that some of the earlier studies reported about astonishing results. For example, lower neutral temperatures were found in the hot season (summer) than in
Table 7 Neutral PET temperature values $\left({ }^{\circ} \mathrm{C}\right)$ obtained through the different analysis techniques

\begin{tabular}{llccc}
\hline Analysis techniques to obtain nPET values & Overall & Spring & Summer & Autumn \\
\hline Mean of PET at TSV = 0 group & 21.0 & 19.2 & 26.0 & 21.6 \\
Median of PET at TSV = 0 group & 20.8 & 18.6 & 25.8 & 22.4 \\
Linear-TSV vs. PET & 17.9 & 17.6 & 16.3 & 18.5 \\
Linear-weighted mean TSV vs. PET bin & 17.9 & 17.7 & 16.4 & 18.5 \\
Linear-mean TSV vs. PET bin & 18.5 & 18.0 & 15.4 & 19.9 \\
Quadratic-TSV vs. PET & 17.4 & 17.1 & 19.7 & 17.4 \\
Quadratic-weighted mean TSV vs. PET bin & 17.4 & 17.2 & 19.7 & 17.4 \\
Quadratic-mean TSV vs. PET bin & 17.1 & 16.8 & 19.8 & 18.0 \\
Probit-half distance of transition curves at 50 \% probability & 17.6 & 17.3 & 19.1 & 18.0 \\
Probit-intersection of transition curves & 17.4 & 17.2 & 19.0 & 17.7 \\
Probit-maximum probability of TSV $=0$ votes & 19.7 & 18.4 & 19.8 & 20.8 \\
\hline
\end{tabular}


the cold season (winter) by Spagnolo and de Dear (2003) in Sydney and by Yahia and Johansson (2013) in Damascus (Table 8). Mahmoud (2011) investigated nine different parkzones in Cairo, and in more than half of the cases the linear regressions used for assessing neutral temperatures led to higher $\mathrm{n} P E T$ in the cold season than in the warm season. The proportion of extreme votes was very high in this study, and the covered $P E T$ interval was extremely narrow in both seasons. The extrapolated $\mathrm{n} P E T$ values fell far away from the covered PET ranges, thereby reducing the credibility of results.

However, most of the earlier studies revealed such seasonal tendencies that are in agreement with the theory and practice of seasonal adaptation. For example neutral temperature was found to - at least slightly — greater in the warmer season(s) than in the cooler season(s) in Tokyo (Nakano and Tanabe 2004), Taiwan (Lin 2009; Lin et al. 2011), Hong Kong (Cheng et al. 2012), Tel Aviv (Cohen et al. 2013), Szeged (Kovács et al. 2015), and in most European cities that participated in the RUROS project (Nikolopoulou and Lykoudis 2006) (Table 8).

\section{Seasonal adaptation and the role of exposure}

According to the glossary for biometeorology (Gosling et al. 2014), adaptation can be defined as the process of adjustment to the actual climate and its effects, which includes physiological acclimatization to warmer/colder temperatures, as well as broad range of behavioral adaptations, e.g., dressing appropriately during hot/cold weather. Besides, several human thermal comfort studies pointed out the significance of other factors like past experiences and future expectations (e.g., Nikolopoulou and Steemers 2003; Nikolopoulou and Lykoudis 2006; Knez and Thorsson 2006, 2008). These factors help the mental adjustment to the geographically and seasonally changeable climate conditions, and facilitate coping with the broad spectrum of outdoor thermal conditions.

Table 7 compared 11 sub-techniques from three main analysis approaches to examine the sensitivity of the resulted $\mathrm{n} P E T$ values to the analysis method. Seven from these techniques revealed the same seasonal tendency in Hungary. Accordingly, local population seems to be adapted to the warmer summer and cooler transient seasons. Indeed, people take behavioral adaptation opportunities such as less clothing in summer, and prepare themselves psychically to the warmer conditions, which explain the highest values in summer. For the transient seasons, the more or less higher autumn value corresponds to the climate background: the investigated autumn months are normally somewhat warmer than the investigated spring months (Table 1). The actual meteorological background of the interviews elucidates also the higher autumn $\mathrm{n} P E T$ : subjects were exposed to slightly warmer thermal conditions during autumn than in spring (Fig. 8).

Figure 8 offers insight into the seasonal climate background of the interviews and its possible consequences on the obtained results. In terms of $T_{\mathrm{a}}$ and $P E T$, summertime interviewees had to face the warmest thermal conditions (Fig. 8a, b). Individuals in autumn experienced broader range of $T_{\mathrm{a}}$ and $P E T$, and this season had slightly higher median $T_{\mathrm{a}}$ and $P E T$ than spring. However, in terms of the heat gain via radiation $\left(T_{\mathrm{mrt}}\right)$, the broadest IQR occurred in spring, and the median in this season was almost as high as in summer (Fig. 8c). This suggests that our subjects stayed more frequently in the sun during spring, even if the solar radiation was too strong.

Indeed, more than $40 \%$ of the subjects exposed themselves to direct sunlight during the field surveys conducted in spring,

Table 8 Neutral temperatures $\left({ }^{\circ} \mathrm{C}\right)$ in seasonal comparison based on the prior outdoor and semi-outdoor thermal comfort studies

\begin{tabular}{|c|c|c|c|c|c|c|c|}
\hline Reference & Location & Index & Technique & Winter & Spring & Summer & Autumn \\
\hline Nakano and Tanabe 2004 & Tokyo, Japan & $S E T^{*}$ & Weighted $M T S V$ vs. SET* bin & 24.9 & 23.9 & 26.9 & 23.4 \\
\hline \multirow[t]{7}{*}{ Nikolopoulou and Lykoudis 2006} & Athens, Greece & \multirow[t]{7}{*}{$T_{\mathrm{a}}$} & \multirow{7}{*}{$\begin{array}{l}\text { Probit-half distance between transition } \\
\text { curves at } 50 \% \text { probab. }\end{array}$} & 21.5 & 24.3 & 28.5 & 19.4 \\
\hline & Thessaloniki, Greece & & & 15.0 & 18.4 & 28.9 & 24.7 \\
\hline & Fribourg, Switz. & & & 11.9 & 13.2 & 15.8 & 13.3 \\
\hline & Milan, Italy & & & 21.1 & 20.7 & 21.5 & 24.6 \\
\hline & Cambridge, UK & & & N/A & 17.6 & 18.0 & 23.2 \\
\hline & Sheffield, UK & & & 10.8 & 11.8 & 15.8 & 16.7 \\
\hline & Kassel, Germany & & & 15.2 & 17.2 & 22.1 & 15.8 \\
\hline Kovács et al. 2015 & Szeged, Hungary & PET & $M T S V$ vs. $P E T$ bin-quadratic & $\mathrm{N} / \mathrm{A}$ & 16.4 & 19.5 & 18.4 \\
\hline Reference & Location & Index & Technique & Cold season & - & Hot season & - \\
\hline \multirow[t]{3}{*}{ Spagnolo and de Dear 2003} & \multirow[t]{3}{*}{ Sydney, Australia } & OUT_SET* & \multirow{3}{*}{$\begin{array}{l}\text { Probit-intersection of transition } \\
\text { curves at } 50 \% \text { probab. }\end{array}$} & 33.3 & & 23.3 & \\
\hline & & PET ${ }^{-}$ & & 28.8 & & 22.9 & \\
\hline & & $T_{\mathrm{a}}$ & & 26.6 & & 23.0 & \\
\hline Lin 2009 & Taichung, Taiwan & PET & $M T S V$ vs. $P E T$ bin-linear & 23.7 & & 25.6 & \\
\hline Lin et al. 2011 & 3 cities in Taiwan & $S E T^{*}$ & $M T S V$ vs. SET* bin-linear & 28.0 & & 29.3 & \\
\hline Cheng et al. 2012 & Hong Kong & PET & $T S V$ vs. $P E T$-linear & 21.0 & & 25.0 & \\
\hline Cohen et al. 2013 & Tel Aviv, Israel & PET & $M T S V$ vs. $P E T$ bin-linear & 22.7 & & 23.9 & \\
\hline \multirow[t]{2}{*}{ Yahia and Johansson 2013} & \multirow[t]{2}{*}{ Damascus, Syria } & PET & $M T S V$ vs. $P E T$ bin-linear & 23.4 & & 15.8 & \\
\hline & & OUT_SET* & $M T S V$ vs. $O U T S S E T^{*}$ bin-linear & 35.1 & & 23.1 & \\
\hline
\end{tabular}


Fig. 8 Thermal background of the interviews in terms of air temperature (a), physiologically equivalent temperature (b), and mean radiant temperature $(\mathbf{c})$
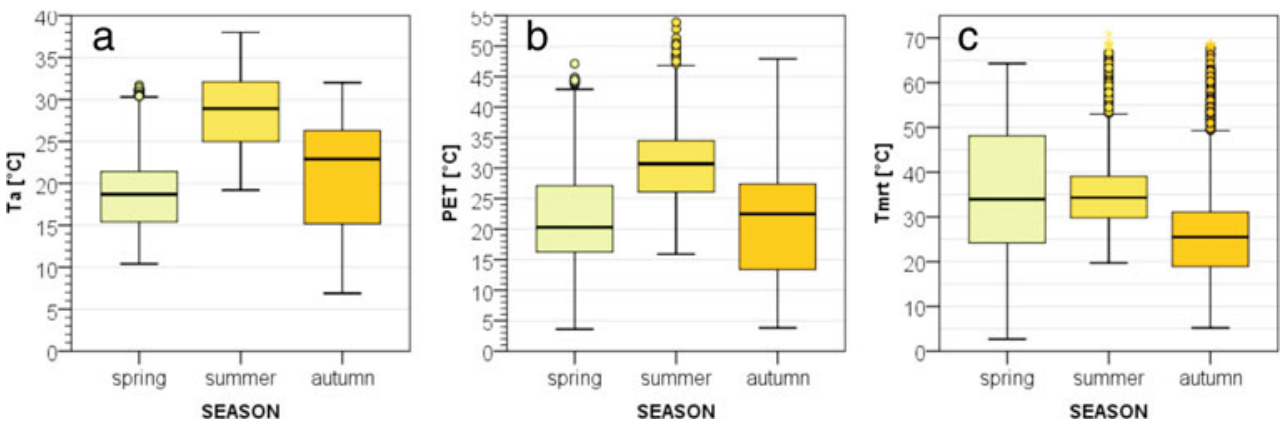

while the proportion of this exposition was below $20 \%$ in summer and autumn (Table 9). Seventy-four percent of the questioned individuals selected a shaded location in summer, and $66 \%$ acted so in autumn.

Taking into account this very clear seasonal exposure-preference, one may conclude that the thermal sensitivity of people as well as their neutral temperature in summer were governed by the reactions of people who stayed in the shade, while the springtime results reflected mostly the reactions of the sun-exposed people. Accordingly, a new research question emerged for the future in order to prove or disprove whether people have the same thermal perception patterns in differently shaded or insolated environments (Kántor in press).

\section{Main conclusions}

This research investigated the outdoor thermal perception patterns regarding the PET index, based on the responses of more than 5800 Hungarians interviewed on popular recreational areas in the city of Szeged. Thermal Sensation Vote was recorded on a semantic differential scale ranging from very cold to very hot and meteorological variables that affect human thermal sensation were measured simultaneously with high accuracy. Three main analysis techniques were adopted with numerous subtechniques in order to reveal seasonal differences in the thermal assessment and especially in the resulted neutral temperature.

The outcomes of this study can be summarized as follows:

- There are significant seasonal differences in Hungarians' neutral temperatures (nPET), especially between summer and the two transient seasons.
- Most of the applied techniques resulted in the same order of $\mathrm{n} P E T$ values, ascending as follows: spring, autumn, and summer. This tendency corresponds to the seasonal climate normal, as well as to the seasonal differences between the actual thermal conditions during the investigations. This outcome supports the theory of thermal adaptation, and is consistent with several earlier studies that revealed seasonal differences in neutral temperature.

- The different analysis techniques led to considerably different $\mathrm{n} P E T$ values, which ranged from 17.1 to $21^{\circ} \mathrm{C}$ in the case of the overall database. Larger differences were found in summer ( 15.4 to $26^{\circ} \mathrm{C}$ ).

- Beside neutral temperatures, the thermal sensitivity of people and the determined thermal sensation zones were also found to be different, depending on both seasons and also on the adopted analysis techniques. The differences were always greater on the marginal parts of the PET scale.

The technique-dependence of the outcome raises the question of the credibility of international comparisons. Therefore, we have to emphasize the importance of developing human-biometeorological-outdoor thermal comfort guidelines regarding not only the measurements, but the applied analytical approaches as well. We could ensure the comparability of the numerous outdoor thermal comfort studies only by following the same measurement methodologies, with especial attention on the type and implementation of the radiation measurements and index calculation (Johansson et al. 2014), as well as by applying the same analysis techniques. This would enable us to synthesize the outcome of the numerous works in this field of science.
Table 9 Number of the interviewees according to seasons and solar exposure (the exposure was sometimes indeterminable because of the clouds)

\begin{tabular}{lllll}
\hline & Spring & Summer & Autumn & Total \\
\hline "sunny": subjects in the sun & 1163 & 151 & 371 & 1685 \\
"shade": subjects in the shade & 940 & 815 & 1260 & 3015 \\
"overcast" conditions: exposure was indeterminable & 689 & 131 & 285 & 1105 \\
Total & 2792 & 1097 & 1916 & 5805 \\
\hline
\end{tabular}




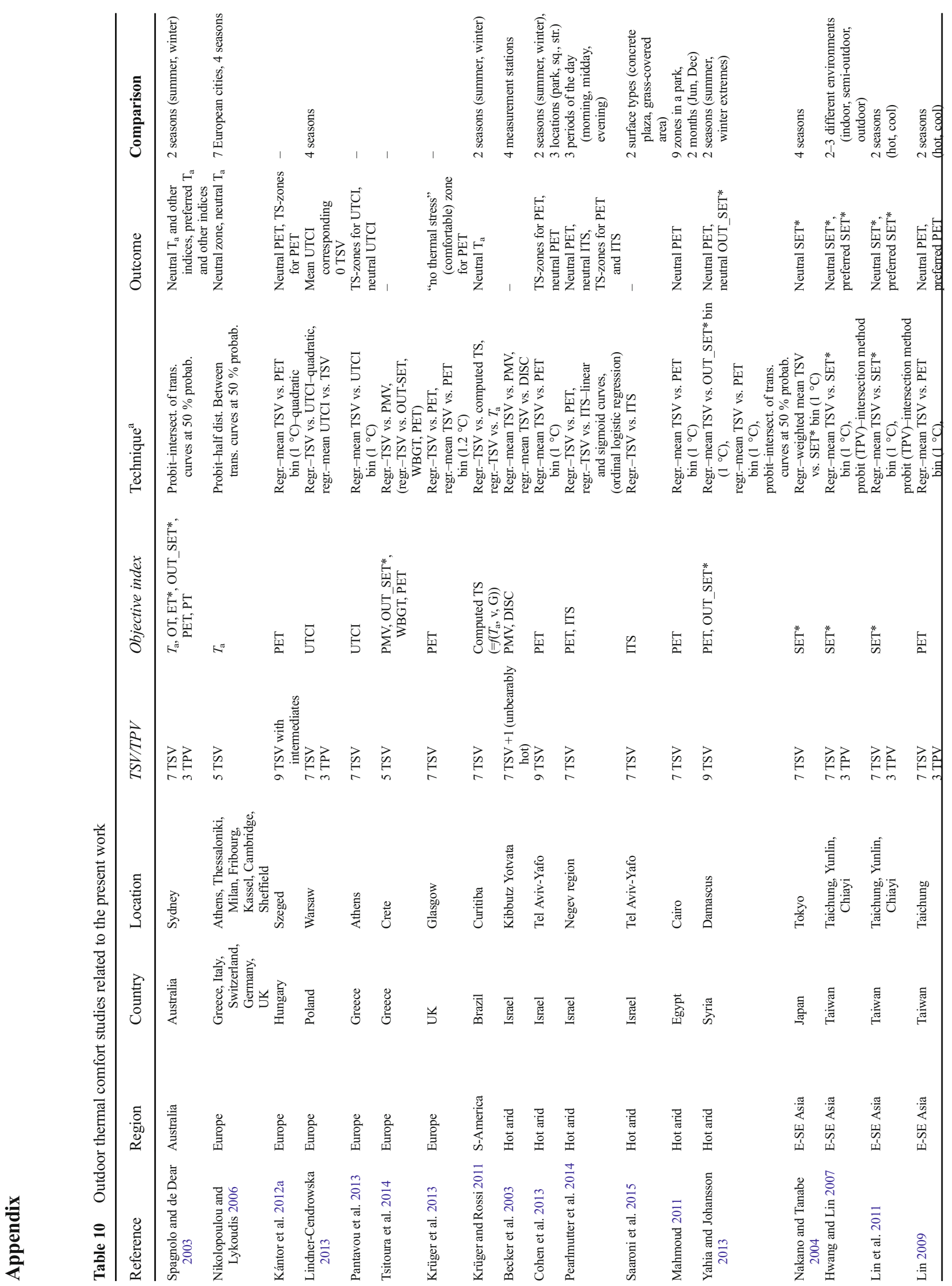




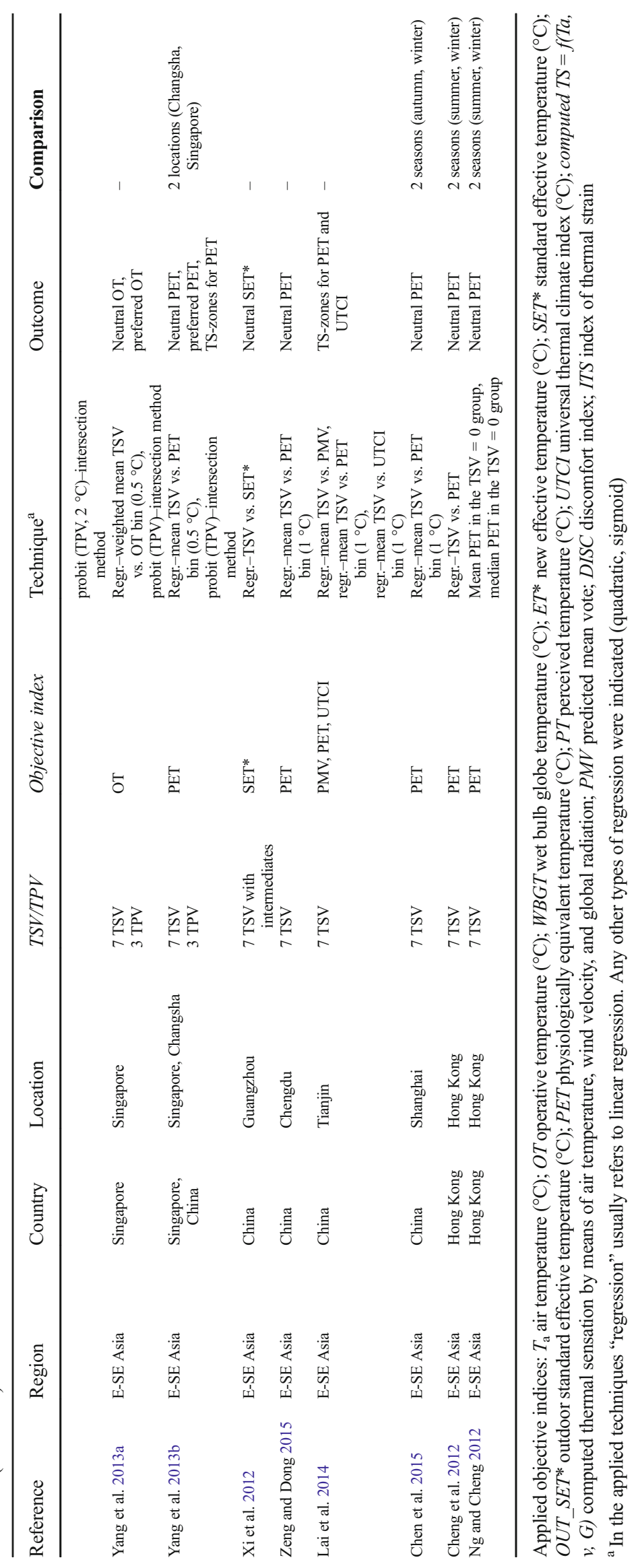



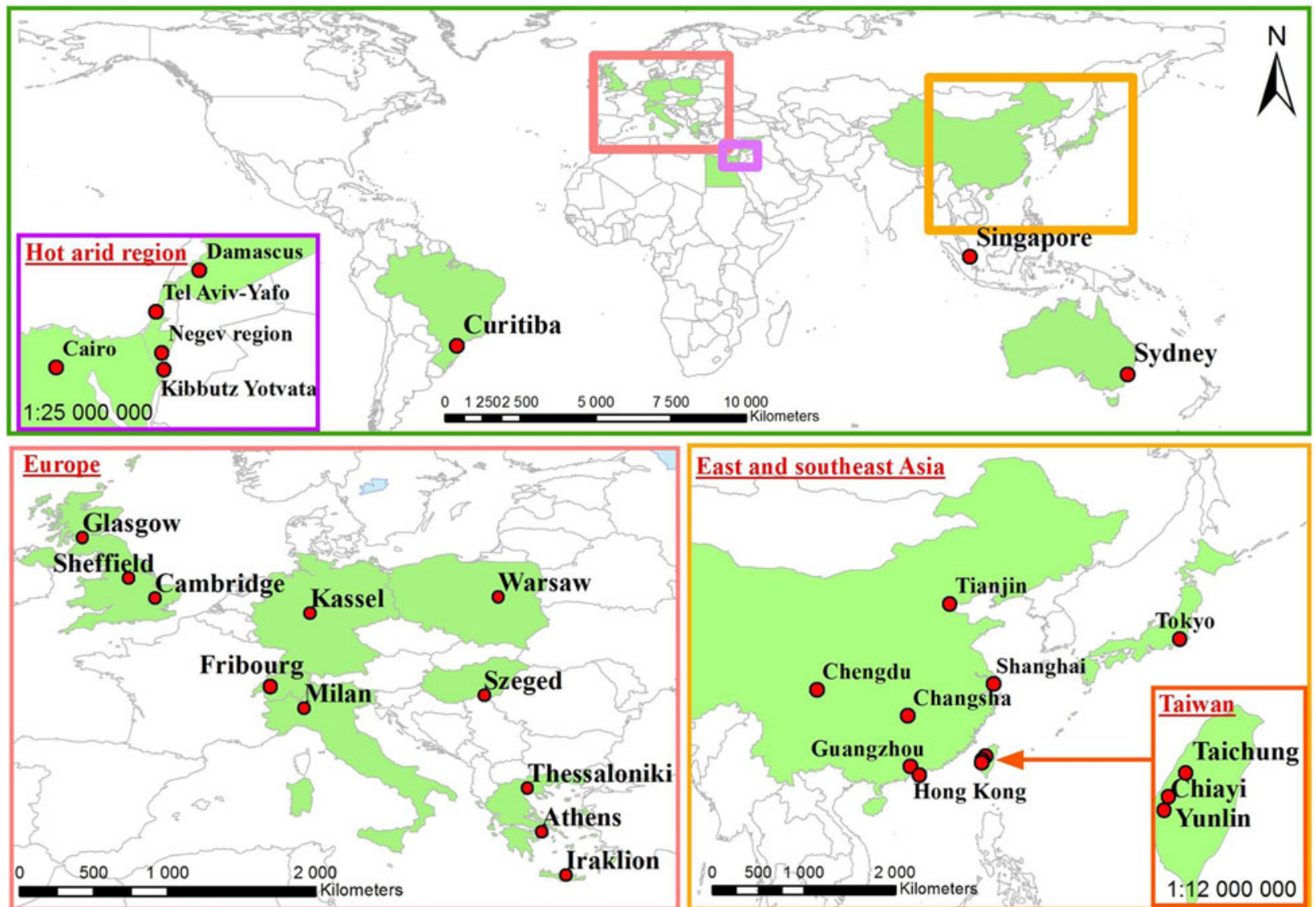

Fig. 9 Geographical location of the most important outdoor thermal comfort studies related to the present work

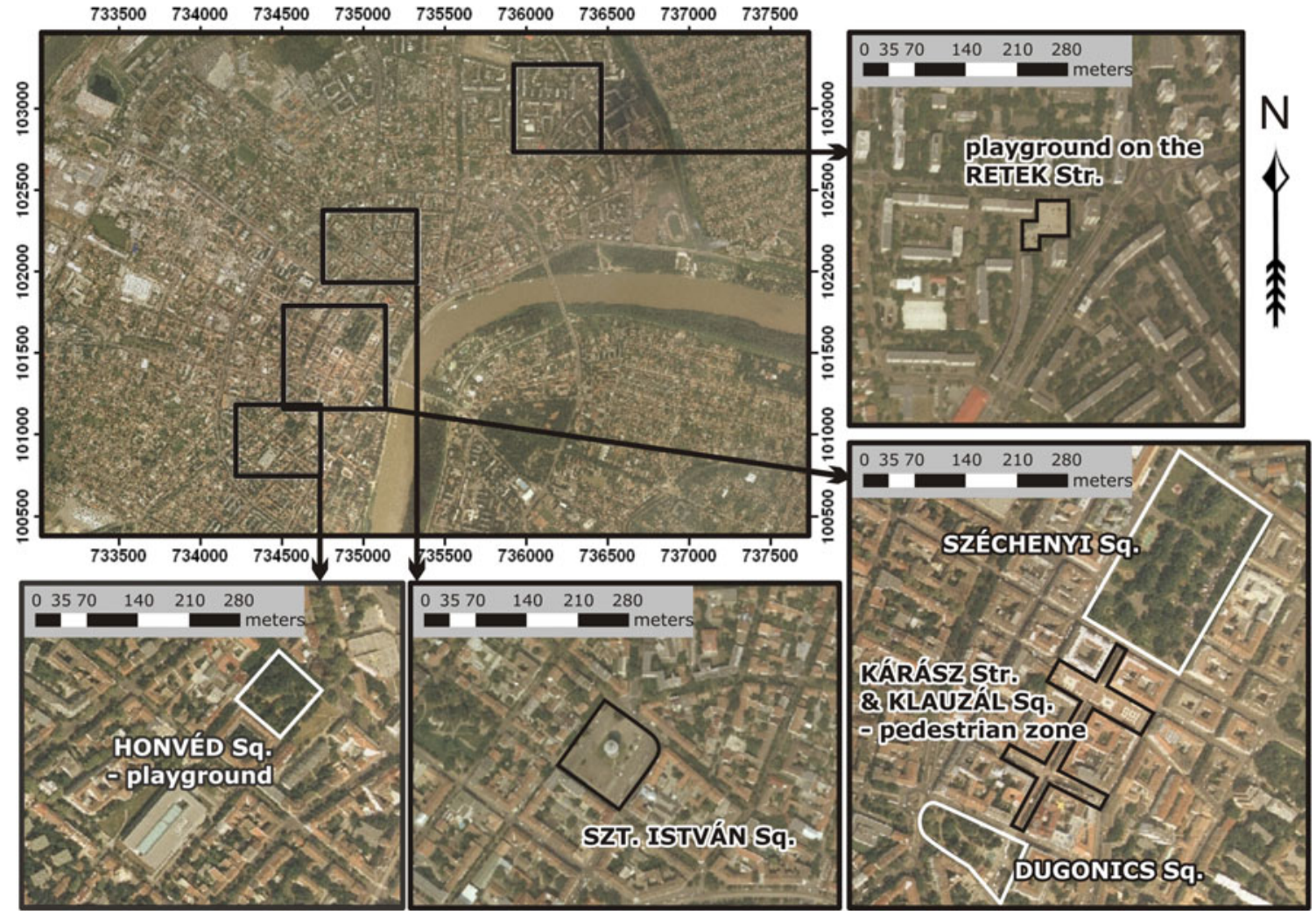

Fig 10 Location of the six study areas in the city of Szeged 


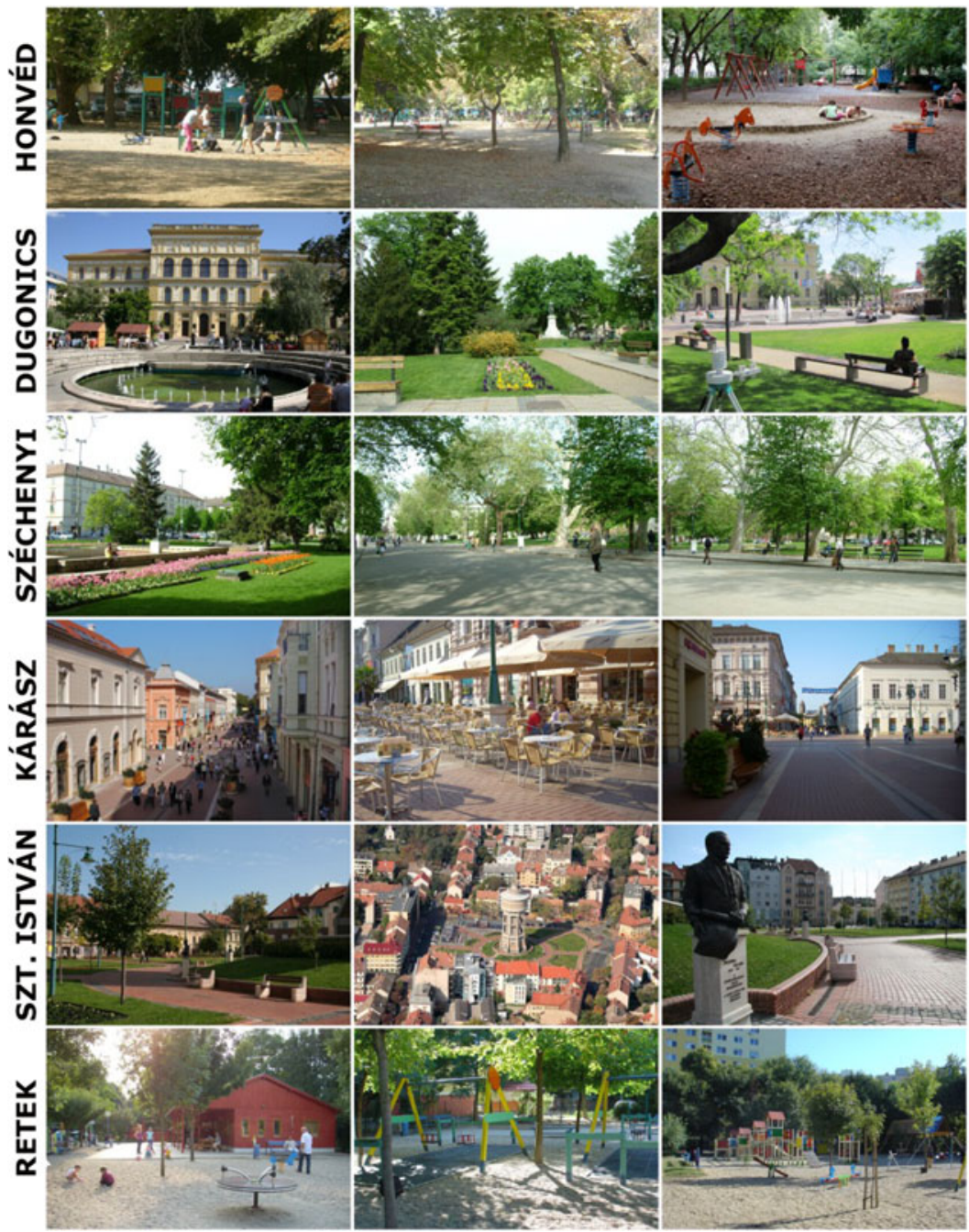

playground, resting place

close to the University Library

light-colored gravel

frayed grass

several mature shade trees

central square, meeting and resting place

venue of greater fairs

complete reconstruction in 2013

gravel, red- and dark-colored paving stone

grass, flower beds, statue, fountain with music

a couple of mature shade trees

central square, meeting and resting place

main venue of greater fairs

asphalt, dark-colored paving stone

large grassy areas, flower beds

fountain, several statues

remarkable mature shade tree stock

main pedestrian zone in Szeged

red-colored paving stone

coffee shops, confectioneries

artificial shading (parasols)

without vegetation

(a couple of potted thuja trees)

little square, periodic local market

complete reconstruction in 2010

red-colored paving stone, grass

flower beds, statues, little fountain

water tower 'The Old Lady of Szeged'

only young trees, almost without shading

protected (fenced) playground with

playhouse and well-maintained facilities

light-colored gravel,

without grassy surface

without proper shading

(mature trees outside the playground)

Fig. 11 Photos and the general description of the six study areas

\section{References}

Ali-Toudert F, Mayer H (2006) Numerical study on the effects of aspect ratio and orientation of an urban street canyon on outdoor thermal comfort in hot and dry climate. Build Environ 41:94-108

Ali-Toudert F, Mayer H (2007a) Thermal comfort in an east-west oriented street canyon in Freiburg (Germany) under hot summer conditions. Theor Appl Climatol 87:223-237

Ali-Toudert F, Mayer H (2007b) Effects of asymmetry, galleries, overhanging facades and vegetation on thermal comfort in urban street canyons. Sol Energy 81:742-754

Andrade H, Vieira R (2007) A climatic study of an urban green space: the Gulbenkian park in Lisbon (Portugal). Finisterra 42:27-46

Ballantyne ER, Hill RK, Spencer JW (1977) Probit analysis of thermal sensation assessments. Int J Biometeorol 21:29-43

Becker S, Potchter O, Yaakov Y (2003) Calculated and observed human thermal sensation in an extremely hot and dry climate. Energ Build $35: 747-756$

Charalampopoulos I, Tsiros I, Chronopoulou-Sereli A, Matzarakis A (2013) Analysis of thermal bioclimate in various urban configurations in Athens, Greece. Urban Ecosyst 16:217-233

Chen L, Ng E (2012) Outdoor thermal comfort and outdoor activities: a review of research in the past decade. Cities 29:118-125
Chen L, Wen Y, Zhang L, Xiang WN (2015) Studies of thermal comfort and space use in an urban park square in cool and cold seasons in Shanghai. Build Environ 94:644-653

Cheng V, Ng E, Chan C, Givoni B (2012) Outdoor thermal comfort study in a sub-tropical climate: a longitudinal study based in Hong Kong. Int J Biometeorol 56:43-56

Cohen P, Potchter O, Matzarakis A (2013) Human thermal perception of Coastal Mediterranean outdoor urban environments. Appl Geogr 37:1-10

Deb C, Ramachandraiah A (2011) A simple technique to classify urban locations with respect to human thermal comfort: proposing the HXG scale. Build Environ 46:1321-1328

Fanger PO (1972) Thermal comfort. McGraw-Hill Book Co, New York Fröhlich D, Matzarakis A (2013) Modeling of changes in thermal bioclimate: examples based on urban spaces in Freiburg, Germany. Theor Appl Climatol 111:547-558

Gómez F, Pérez Cueva A, Valcuende M, Matzarakis A (2013) Research on ecological design to enhance comfort in open spaces of a city (Valencia, Spain). Utility of the physiological equivalent temperature (PET). Ecol Eng 57:27-39

Gosling SN, Bryce EK, Dixon PG, et al. (2014) A glossary for biometeorology. Int J Biometeorol 58:277-308

Gulyás Á, Unger J, Matzarakis A (2006) Assessment of the microclimatic and human comfort conditions in a complex urban environment: modelling and measurements. Build Environ 41:1713-1722 
Holst J, Mayer H (2011) Impacts of street design parameters on humanbiometeorological variables. Meteorol Z 20:541-552

Höppe P (1992) Ein neues Verfahren zur Bestimmung der mittleren Strahlungstemperatur im Freien [A new method to determine the mean radiant temperature outdoors]. Wetter und Leben 44:147-151

Höppe P (1999) The physiological equivalent temperature - a universal index for the biometeorological assessment of the thermal environment. Int J Biometeorol 43:71-75

Huttner S, Bruse M, Dostal P (2008) Using ENVI-met to simulate the impact of global warming on the microclimate in central European cities. Ber Meteor Inst Albert-Ludwigs Univ Freiburg 18:307-312

Hwang R-L, Lin T-P (2007) Thermal comfort requirements for occupants of semi-outdoor and outdoor environments in hot-humid regions. Architect Sci Rev 50:357-364

Hwang R-L, Lin T-P, Matzarakis A (2011) Seasonal effects of urban street shading on long-term outdoor thermal comfort. Build Environ 46: $863-870$

IPCC (2014) Climate Change 2014: synthesis report, 2014. Contribution of Working Groups I, II and III to the Fifth Assessment Report of the Intergovernmental Panel on Climate Change [(Core Writing Team, Pachauri RK, Meyer LA (eds)]. IPCC, Geneva

Johansson E, Emmanuel R (2006) The influence of urban design on outdoor thermal comfort in the hot, humid city of Colombo, Sri Lanka. Int J Biometeorol 51:119-133

Johansson E, Thorsson S, Emmanuel R, Krüger E (2014) Instruments and methods in outdoor thermal comfort studies - the need for standardization. Urban Climate 10:346-366

Kántor N, Unger J (2011) The most problematic variable in the course of human biometeorological comfort assessment - the mean radiant temperature. Cent Eur J Geosci 3:90-100

Kántor N, Unger J, Gulyás Á (2012a) Subjective estimations of thermal environment in recreational urban spaces-Part 2: international comparison. Int J Biometeorol 56:1089-1101

Kántor N, Égerházi LA, Unger J (2012b) Subjective estimation of thermal environment in recreational urban spaces-Part 1: investigations in Szeged, Hungary. Int J Biometeorol 56:1075-1088

Kántor N, Tsai KT, Égerházi L, Lin T-P (2014) Outdoor thermal comfort requirements of Taiwanese and Hungarians in the warm months. Presentation and extended abstract on the 20th International Congress of Biometeorology, 28 September-2 October 2014, Cleveland, Ohio. Paper number: 5C.3

Knez I, Thorsson S (2006) Influences of culture and environmental attitude on thermal, emotional and perceptual evaluations of a public square. Int J Biometeorol 50:258-268

Knez I, Thorsson S (2008) Thermal, emotional and perceptual evaluations of a park: cross-cultural and environmental attitude comparisons. Build Environ 43:1483-1490

Kovács A, Unger J, Gál CV, Kántor N (2015) Adjustment of the thermal component of two tourism climatological assessment tools using thermal perception and preference surveys from Hungary. Theor Appl Climatol doi:10.1007/s00704-015-1488-9

Krüger EL, Rossi FA (2011) Effect of personal and microclimatic variables on observed thermal sensation from a field study in southern Brazil. Build Environ 46:690-697

Krüger EL, Drach P, Emmanuel R, Corbella O (2013) Assessment of daytime outdoor comfort levels in and outside the urban area of Glasgow, UK. Int J Biometeorol 57:521-533

Krüzselyi I, Bartholy J, Horányi A, Pieczka I, Pongrácz R, Szabó P, Szépszó G, Torma CS (2011) The future climate characteristics of the Carpathian Basin based on a regional climate model mini-ensemble. Adv Sci Res 6:69-73

Lai D, Guo D, Hou Y, Lin C, Chen Q (2014) Studies of outdoor thermal comfort in northern China. Build Environ 77:110-118

Lenzholzer S (2010) Engrained experience - a comparison of microclimate perception schemata and microclimate measurements in Dutch urban squares. Int J Biometeorol 54:141-150
Lin T-P (2009) Thermal perception, adaptation and attendance in a public square in hot and humid regions. Build Environ 44:2017-2026

Lin T-P, Matzarakis A (2008) Tourism climate and thermal comfort in Sun Moon Lake, Taiwan. Int J Biometeorol 52:281-290

Lin T-P, Matzarakis A, Hwang RL (2010) Shading effect on long-term outdoor thermal comfort. Build Environ 45:213-221

Lin T-P, de Dear R, Hwang R-L (2011) Effect of thermal adaptation on seasonal outdoor thermal comfort. Int J Climatol 31:302-312

Lindner-Cendrowska K (2013) Assessment of bioclimatic conditions in cities for tourism and recreational purposes (a Warsaw case study). Geogr Pol 86:55-66

Mahmoud AHA (2011) Analysis of the microclimatic and human comfort conditions in an urban park in hot and arid regions. Build Environ 46:2641-2656

Matzarakis A, Endler C (2010) Climate change and thermal bioclimate in cities: impacts and options for adaptation in Freiburg, Germany. Int J Biometeorol 54:479-483

Matzarakis A, Mayer H (1996) Another kind of environmental stress: thermal stress. WHO Newsl 18:7-10

Matzarakis A, Mayer H, Iziomon MG (1999) Application of a universal thermal index: physiological equivalent temperature. Int $\mathrm{J}$ Biometeorol 43:76-84

Matzarakis A, Rutz F, Mayer H (2007) Modelling radiation fluxes in simple and complex environments - application of the RayMan model. Int J Biometeorol 51:323-334

Matzarakis A, Rutz F, Mayer H (2010) Modelling radiation fluxes in simple and complex environments: basics of the RayMan model. Int J Biometeorol 54:131-139

Mayer H (2008) KLIMES - a joint research project on human thermal comfort in cities. Ber Meteor Inst Albert-Ludwigs Univ Freiburg 17: $101-117$

Mayer H, Höppe P (1987) Thermal comfort of man in different urban environments. Theor Appl Climatol 38:43-49

Mayer H, Holst J, Dostal P, Imbery F, Schindler D (2008) Human thermal comfort in summer within an urban street canyon in Central Europe. Meteorol Z 17:241-250

Müller N, Kuttler W, Barlag AB (2014) Counteracting urban climate change: adaptation measures and their effect on thermal comfort. Theor Appl Climatol 115:243-257

Nakano J, Tanabe S-I (2004) Thermal comfort and adaptation in semioutdoor environments. ASHRAE Trans 110:543-553

Ng E, Cheng V (2012) Urban human thermal comfort in hot and humid Hong Kong. Energ Build 55:51-65

Nikolopoulou M, Lykoudis S (2006) Thermal comfort in outdoor urban spaces: analysis across different European countries. Build Environ 41:1455-1470

Nikolopoulou M, Steemers K (2003) Thermal comfort and psychological adaptation as a guide for designing urban spaces. Energ Build 35: 95-101

Nikolopoulou M, Baker N, Steemers K (2001) Thermal comfort in outdoor urban spaces: understanding the human parameter. Sol Energy 70:227-235

Pantavou K, Theoharatos G, Santamouris M, Asimakopoulos D (2013) Outdoor thermal sensation of pedestrians in a Mediterranean climate and a comparison with UTCI. Build Environ 66:82-95

Pearlmutter D, Jiao D, Garb Y (2014) The relationship between bioclimatic thermal stress and subjective thermal sensation in pedestrian spaces. Int J Biometeorol 58:2111-2127

Pongrácz R, Bartholy J, Bartha EB (2013) Analysis of projected changes in the occurrence of heat waves in Hungary. Adv Geosci 35:115122

Rupp RF, Vásquez NG, Lamberts R (2015) A review of human thermal comfort in the built environment. Energ Build 105:178-205

Saaroni H, Pearlmutter D, Hatuka T (2015) Human-biometeorological conditions and thermal perception in a Mediterranean coastal park. Int J Biometeorol 59:1347-1362 
Shashua-Bar L, Pearlmutter D, Erell E (2011) The influence of trees and grass on outdoor thermal comfort in a hot-arid environment. Int J Climatol 31:1498-1506

Shashua-Bar L, Tsiros IX, Hoffman M (2012) Passive cooling design options to ameliorate thermal comfort in urban streets of a Mediterranean climate (Athens) under hot summer conditions. Build Environ 57:110-119

Spagnolo J, de Dear R (2003) A field study of thermal comfort in outdoor and semi-outdoor environments in subtropical Sydney Australia. Build Environ 38:721-738

Stathopoulos T, Wu H, Zacharias J (2004) Outdoor human comfort in an urban climate. Build Environ 39:297-305

Streiling S, Matzarakis A (2003) Influence of single and small clusters of trees on the bioclimate of a city: a case study. J Arboric 29:309-316

Thorsson S, Lindqvist M, Lindqvist S (2004) Thermal bioclimatic conditions and patterns of behaviour in an urban park in Göteborg, Sweden. Int J Biometeorol 48:149-156

Tsitoura M, Tsoutsos T, Daras T (2014) Evaluation of comfort conditions in urban open spaces. Application in the island of Crete. Energy Convers Manag 86:250-258

Tung C-H, Chen C-P, Tsai K-T, Kántor N, Hwang R-L, Matzarakis A, Lin T-P (2014) Outdoor thermal comfort characteristics in the hot and humid region from a gender perspective. Int $\mathrm{J}$ Biometeorol 58: 1927-1939
UNFPA (2011) The state of world population 2011. Report of the United Nations Population Fund. UNFPA, New York

Unger J, Lelovics E, Gál T (2014) Local climate zone mapping using GIS methods in Szeged. Hung Geogr Bull 63:29-41

Xi T, Li Q, Mochida A, Meng Q (2012) Study on the outdoor thermal environment and thermal comfort around campus clusters in subtropical urban areas. Build Environ 52:162-170

Yahia MW, Johansson E (2013) Evaluating the behaviour of different thermal indices by investigating various outdoor urban environments in the hot dry city of Damascus, Syria. Int J Biometeorol 57:615-630

Yang W, Wong NH, Jusuf SK (2013a) Thermal comfort in outdoor urban spaces in Singapore. Build Environ 59:426-435

Yang W, Wong NH, Zhang G (2013b) A comparative analysis of human thermal conditions in outdoor urban spaces in the summer season in Singapore and Changsha, China. Int J Biometeorol 57:895-907

Yin JF, Zheng YF, Wu RJ, Tan JG, Ye DX, Wang W (2012) An analysis of influential factors on outdoor thermal comfort in summer. Int $\mathrm{J}$ Biometeorol 56:941-948

Zeng Y, Dong L (2015) Thermal human biometeorological conditions and subjective thermal sensation in pedestrian streets in Chengdu, China. Int J Biometeorol 59:99-108 